\title{
Polo-like kinase 1, on the rise from cell cycle regulation to prostate cancer development
}

\author{
Jijing Luo, Xiaoqi Liu ${ }^{\bowtie}$ \\ Department of Biochemistry, Purdue University, West Lafayette, IN 47907, USA \\ $\square$ Correspondence: liu8@purdue.edu \\ Received January 1, 2012 Accepted February 4, 2012
}

\begin{abstract}
Polo-like kinase 1 (Plk1), a well-characterized member of serine/threonine kinases Plk family, has been shown to play pivotal roles in mitosis and cytokinesis in eukaryotic cells. Recent studies suggest that Plk1 not only controls the process of mitosis and cytokinesis, but also, going beyond those previously described functions, plays critical roles in DNA replication and Pten null prostate cancer initiation. In this review, we briefly summarize the functions of PIk1 in mitosis and cytokinesis, and then mainly focus on newly discovered functions of Plk1 in DNA replication and in Ptennull prostate cancer initiation. Furthermore, we briefly introduce the architectures of human and mouse prostate glands and the possible roles of Plk1 in human prostate cancer development. And finally, the newly chemotherapeutic development of small-molecule Plk1 inhibitors to target Plk1 in cancer treatment and their translational studies are also briefly reviewed.
\end{abstract}

KEYWORDS polo-like kinase 1 , cell cycle regulation, Orc2, DNA replication, early embryonic development, prostate cancer, Pten, cancer initiation and progression, translational studies

\section{INTRODUCTION}

Polo gene, encoding an important enzyme, was first identified in fruit fly ( $D$. melanogaster) in two decades ago (Llamazares et al., 1991). It was shown that polo gene, whose mutations led to abnormal mitosis, plays a critical role in mitosis of Drosophila larval neuroblasts. Subsequently, the homolog of polo gene was identified and cloned from murine ( $M$. musculus) hematopoietic progenitor cells and shown to encode a protein kinase that is highly conserved with fruit fly's polo gene and named polo-like kinase gene, designated as Plk gene (Clay et al., 1993). Since the discovery of polo gene, a wealth of functional information on Plks has been collected from various organisms. Plks belong to a family of serine/threonine kinases, which are highly conserved among eukaryotes from yeast to mammals. Both budding yeast ( $S$. cerevisiae) and fission yeast (S. pombe) have only one homolog of Plks, designated as Cdc5 and Plo1, respectively. Both of them are known to play important roles in cell cycle regulation, including mitotic entry, mitotic exit, and cytokinesis (Bahassi, 2011). Three known Plks (Plx1-3) were identified in Xenopus laevis (Santamaria et al., 2007) and five Plks (Plk1-5) were found in mammals (Glover et al., 1998; Barr et al., 2004; Andrysik et al., 2010). Recent advances in basic functional studies of Plks in various organisms have shown that these Plks have multiple functions in tight regulation of the cell cycle progression. Mutations in these genes lead to abnormal cell cycle in these organisms. All Plks in mammalian cells have a similar structure, with a canonical serine/threonine kinase domain at the $\mathrm{N}$ terminus, followed by a regulatory domain containing two polo-box domains (PBD) at the $\mathrm{C}$ terminus (Fig. 1A). Although similar architecture was shown among Plk members, the human Plk1, 2, 3, 4, and 5 genes have distinct chromosomal localization and expression profiles, and show unique biological functions from extensive studies in the past two decades (Hudson et al., 2001; Ma et al., 2003; Barr et al., 2004).

Plk1, a well-characterized member of Plk family, localizes to various subcellular structures, such as centrosomes, spindle poles, kinetochores, midzones and midbodies by PBD binding (Elia et al., 2003a) to its substrates. Plk1 mediates many mitotic events, including entry into mitosis, centrosome maturation, assembly of the bipolar spindle, sister chromatid splitting, activation of the Anaphase-Promoting Complex/ Cyclosome (APC/C), and exit from mitosis with the initiation of cytokinesis (Fig.1B). Many excellent reviews have exten- 
A

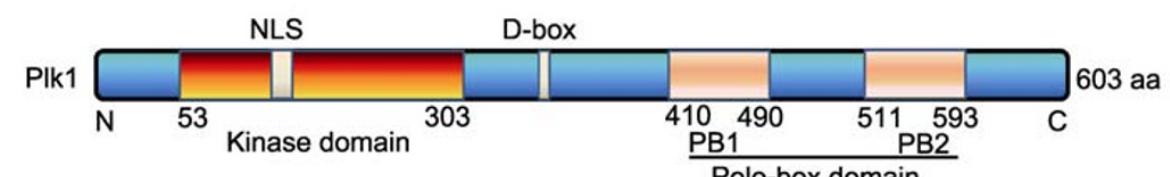

Polo-box domain

B

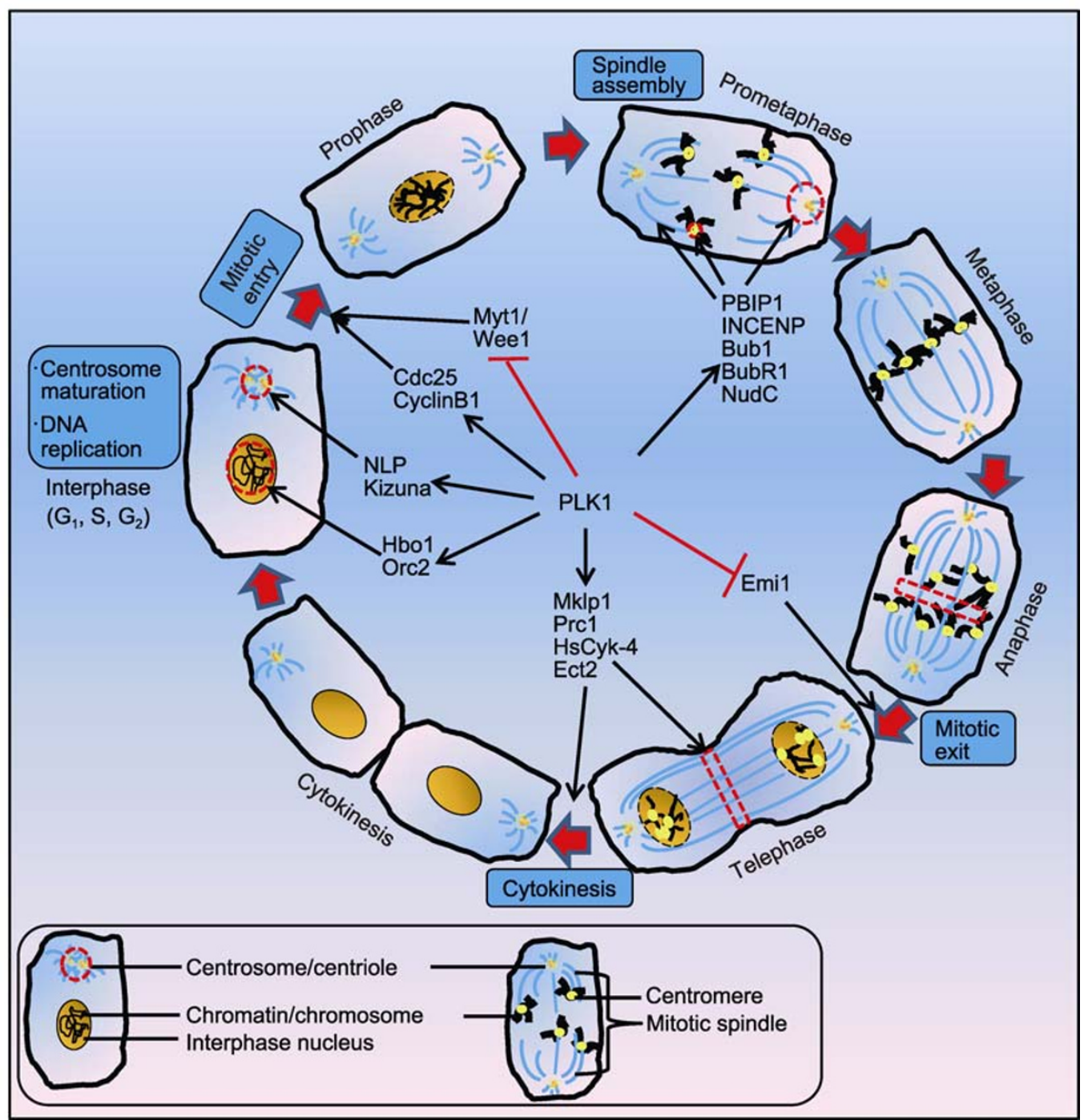

Figure 1. The schematic structure of Plk1 and its roles in cell cycle regulation. (A) Domain structure of human Plk1. The length of amino acid (aa) is shown on the right. The positions of kinase domain and polo-box domain PB1 and PB2 are depicted, and the numbers designate the start and the end positions of the domains. (B) A schematic diagram of the mammalian cell cycle, emphasizing the functions of Plk1 in multiple stages of cell cycle regulation. Functions of Plk1 and its substrates are listed in blue boxes. Localization of Plk1 to subcellular structures is indicated by red dashed objects. Related subcellular structures of cells are indicated in inset box

sively addressed these aspects (Glover et al., 1998; Barr et al., 2004; van de Weerdt and Medema, 2006; Barr and Gruneberg, 2007; Petronczki et al., 2008; Takaki et al., 2008; Archambault and Glover, 2009; Strebhardt, 2010). In addition, increasing evidences show that the functions of Plk1 go be- yond its roles in mitotic regulation. First, recent publications on new Plk1 substrates reveal that Plk1 not only functions in mitotic regulation but also plays pivotal roles in other cell cycle phases, and even some novel functions go beyond the cell cycle regulation. For example, diverse functions of sub- 
strates of Plk1 indicate that Plk1 mediates the functions involving microtubule dynamics (CLIP-170 and p150 glued) (Yang et al., 2009a; Li et al., 2010a, 2010b), DNA replication (Hbo1 and Orc2) (Fig. 2) (Wu and Liu, 2008; Song et al., 2011), chromosome dynamics (Topo II and Trf1) (Li et al., 2008; Wu et al., 2008), p53 regulation (Topors and GTSE1) (Yang et al., 2009b; Liu et al., 2010a), and recovery from the $\mathrm{G}_{2}$ DNA damage checkpoint (van Vugt et al., 2010). Second, a recent publication of our lab links Plk1 to the tumor suppressor Pten, revealing an important role of Plk1 in cancer initiation and progression (Liu et al., 2011). The mitotic functions of Plk1 have been thoroughly discussed in recent reviews (Strebhardt and Ullrich, 2006; van de Weerdt and Medema, 2006; Petronczki et al., 2008; Lee et al., 2008; Takaki et al., 2008; Liu et al., 2010b; Park et al., 2010; Strebhardt, 2010; Bahassi, 2011). In the current review, we will briefly introduce the functions of Plk1 in mitosis and go beyond mitosis to highlight the recent surprising findings of Plk1 functions in DNA replication and prostate cancer development.

\section{ROLES OF PLK1 IN CELL CYCLE REGULATION}

\section{Polo-box domain dependent binding of PIk1 to target its substrates}

The most striking feature of Plk1 is that it orderly changes its localization to various subcellular structures during mitotic progression, both spatially and temporally (Fig. 1B; Table 1) (Strebhardt, 2010). During cell cycle progression, Plk1 binds to the pre-replicative complex in interphase (Fig. 2) (Song et al., 2011), sublocalizes to centrosomes in prophase, becomes enriched at kinetochores in pro-metaphase and metaphase, then is recruited to the central spindles in anaphase, and finally redistributes to the midbodies in telephase and cytokinesis (Fig. 1B). How does Plk1 precisely and properly translocalize to these subcellular structures to mediate the specific events of cell cycle? The C-terminal PBD of Plk1 was first found to function as a phosphor-peptide binding domain in 2003 (Elia et al., 2003a). This discovery, as an answer to the above question, suggests a mechanism of Plk1

Table 1 Substrates of polo-like kinase 1 in cell cycle regulation

\begin{tabular}{|c|c|c|c|}
\hline Substrates & Phosphorylation sites & Functions & References \\
\hline \multicolumn{4}{|l|}{ S phase } \\
\hline Hbo1 & Ser57 & $\begin{array}{l}\text { Histone acetyltransferase. Required for pre-RC formation and } \\
\text { DNA replication licensing }\end{array}$ & Wu and Liu, 2008 \\
\hline Orc2 & Ser188 & $\begin{array}{l}\text { Component of ORC. Facilitating DNA replication under stressful } \\
\text { conditions }\end{array}$ & Song et al., 2011 \\
\hline \multicolumn{4}{|l|}{$\mathrm{G}_{2} / \mathrm{M}$ phase } \\
\hline NLP & Ser237, 1463 & Ninein-like protein for centrosome maturation & Casenghi et al., 2003 \\
\hline Kizuna & Thr379 & Centrosome architecture maintenance & Oshimori et al., 2006 \\
\hline Cdc25 & Ser198 & $\begin{array}{l}\text { Phosphatase. Activation of Cdk1/Cyclin B1 complex for pro- } \\
\text { moting } \mathrm{G}_{2} / \mathrm{M} \text { phase transition }\end{array}$ & Toyoshima-Morimoto et al., 2002 \\
\hline Cyclin B1 & Ser133,147 & $\begin{array}{l}\text { Activation of Cdk1/Cyclin B1 complex on centrosome for promot- } \\
\text { ing } \mathrm{G}_{2} / \mathrm{M} \text { phase transition }\end{array}$ & Toyoshima-Morimoto et al., 2001 \\
\hline Myt1 & Ser426, Thr495 & Cdk1 inhibitory kinase, regulating Cdk1 activity & Nakajima et al., 2003 \\
\hline Wee1 & Ser53 & Cdk1 inhibitory kinase, regulating Cdk1 activity & Watanabe et al., 2004 \\
\hline \multicolumn{4}{|l|}{ M phase } \\
\hline PBIP1 & Thr78 & $\begin{array}{l}\text { PBD interacting protein. Recruitment of Plk1 to kinetochores/ } \\
\text { centrosomes }\end{array}$ & Kang et al., 2006 \\
\hline INCENP & $N D^{*}$ & $\begin{array}{l}\text { The inner centromere protein. Recruitment of Plk1 to kinetocho- } \\
\text { res/centrosomes }\end{array}$ & Goto et al., 2006 \\
\hline Bub1 & ND & Mitotic checkpoint kinase. Targeting Plk1 at kinetochores & Qi et al., 2006 \\
\hline BubR1 & Ser676 & $\begin{array}{l}\text { Spindle checkpoint component. Recruitment of Plk1 to kineto- } \\
\text { chores/centrosomes }\end{array}$ & Elowe et al., 2007 \\
\hline NudC & Ser274, 326 & Recruitment of Plk1 to kinetochores & Zhou et al., 2003 \\
\hline Emi1 & Ser145, 149 & APC/C complex inhibitor, regulating APC/C complex activity & $\begin{array}{l}\text { Hansen et al., 2004; Moshe et al., } \\
2004\end{array}$ \\
\hline \multicolumn{4}{|c|}{ Cytokinesis } \\
\hline Mklp1 & Ser904, 905 & $\begin{array}{l}\text { Motitic kinesin-like motor protein. Component of centraspindlin. } \\
\text { Recruiting Plk1 to midzone in cytokinesis regulation }\end{array}$ & Liu et al., 2004 \\
\hline Prc1 & Thr602 & Recruitment of Plk1 to spindle midzone in cytokinesis regulation & Neef et al., 2007 \\
\hline HsCyk-4 & $\begin{array}{l}\text { Ser149, } 157,164 \\
170,214,260\end{array}$ & $\begin{array}{l}\text { Component of centraspindlin, recruitment of Ect2 to spindle } \\
\text { midzone and then activation of Ect } 2\end{array}$ & $\begin{array}{l}\text { Wolfe et al., 2009; Burkard et al., } \\
2009\end{array}$ \\
\hline Ect2 & Thr412 & $\begin{array}{l}\text { Rho guanine-nucleotide exchange factor (RhoGEF), for RhoA } \\
\text { activation in cytokinesis regulation }\end{array}$ & Niiya et al., 2006 \\
\hline
\end{tabular}

${ }^{*}$ Not determined 


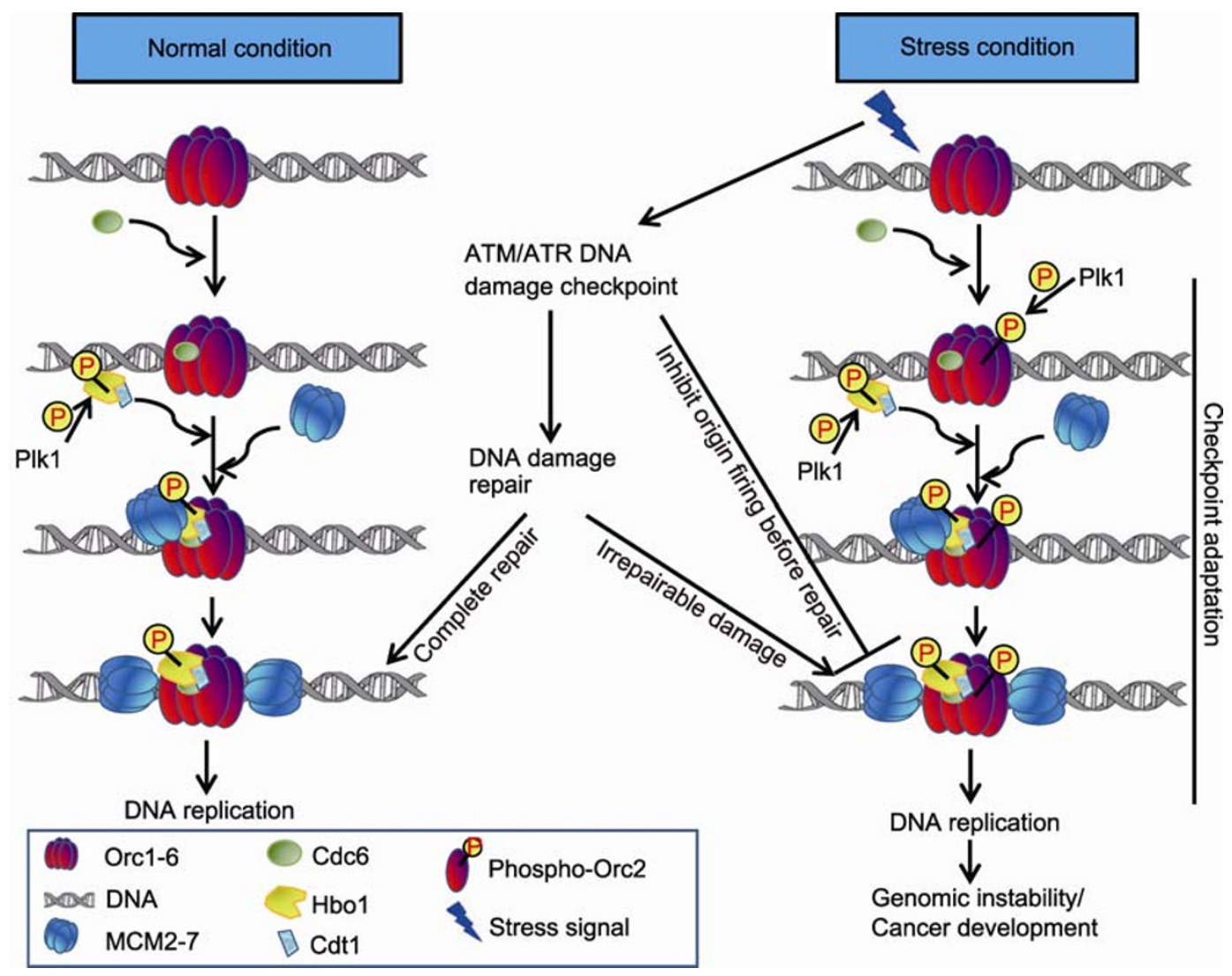

Figure 2. The model of the mechanism of Plk1 in maintaining the stability of pre-replicative complex for facilitating DNA replication under stressful conditions. In normal condition, Plk1 phosphorylated Hbo1 is required pre-RC formation and DNA replication licensing (left panel). Under stressful conditions, stress signal causes DNA damage and results in ATM/ATR-mediated checkpoint signaling pathway activation and cell cycle arrest for DNA repair (middle panel). Meanwhile, Plk1 recruits to pre-RC and phosphorylates Orc2 to maintain the stability of pre-RC for facilitating DNA replication and therefore reentering the cell cycle with complete repair of damaged DNA (checkpoint recovery) or with irrepairable damaged DNA (checkpoint adaptation). Checkpoint adaptation might result in genomic instability and be the cause of cancer development.

targeting subcellular structures by which Plk1 can dock, via its PBD, to specifically phosphorylated targets (Petronczki et al., 2008). Supporting this model, the subsequent crystallization studies of human PBD of Plk1 showed how the phosphor-peptides bind to an interface that is formed between the two polo boxes (Cheng et al., 2003; Elia et al., 2003b). In addition, Plk1 binds to target proteins that have previously been marked as docking sites through a 'priming' phosphorylation (Elia et al., 2003a) by Cdc2 or other proline-directed kinases, or by self-priming phosphorylation in vivo (Park et al., 2010). The 'priming' phosphorylation to generate docking sites for Plk1 and the different subcellular distributions of Plk1 docking partners confer very important elements of temporal and spatial control over the activity of Plk1, respectively (Barr et al., 2004). Thus, PBD-dependent binding of Plk1 targeting its substrates confers Plk1 the ability to orderly regulate various cell cycle events in a temporal and spatial manner.

\section{Plk1, a key regulator in mitosis and cytokinesis}

The roles of Plk1 in mitosis and cytokinesis have been well-established. In prophase, Plk1 is essential for centrosome functions and the assembly of bipolar spindles (Fig. 1B). One of these functions is the recruitment of $\gamma$-tubulin ring complexes $(\gamma$-TuRC), which can nucleate new microtubules, to centrosomes during prophase (Lane and Nigg, 1996). This process is referred to as centrosome maturation. Ninein-like protein (NLP), a component of the centrosome and a substrate of Plk1, recruits $\gamma$-TuRC and stimulates microtubule nucleation during interphase (Casenghi et al., 2003). Phosphorylation of NLP by Plk1 at both Ser237 and Ser1463 sites leads to its dissociation from centrosome during mitosis and might facilitate the recruitment of $\gamma$-TuRC and switch the centrosome from interphase state to the mitotic state (Table 1) (Casenghi et al., 2003, 2005). Another substrate of Plk1, Kizuna, is essential for the mitotic centrosome architecture maintenance (Fig. 1B; Table 1) (Oshimori et al., 2006). De- 
pletion of Kizuna or inhibition of its phosphorylation by Plk1 leads to the fragmentation and dissociation of pericentriolar material from centrioles in pro-metaphase, and results in multipolar spindles.

During mitotic entry, Plk1 controls the activity of Cdk1/ Cyclin B1 complex and promotes the $\mathrm{G}_{2} / \mathrm{M}$ phase transition (Fig. 1B). Cdk1/Cyclin B1, the key driver for the mitotic progression, is controlled by sophisticated regulatory network to prevent its being prematurely activated before the completion of DNA replication to maintain the genome integrity. The Cdk1/Cyclin B1 complex is kept inactive by inhibitory phosphorylation of Cdk1 at Thr14 and Tyr15 by Wee1 and Myt1 kinases, respectively, although with the accumulation of $\mathrm{Cy}$ clin $B 1$ during $G_{2}$ phase. At the onset of mitosis, Plk1 activates Cdk1/Cyclin B1 by both activating phosphorylation of positive regulator Cdc25 and inhibitory phosphorylation of negative regulators, Wee1 and Myt1 (Fig. 1B; Table 1) (Kumagai and Dunphy, 1996; Inoue and Sagata, 2005). In addition, Cyclin B1 is also a physiological substrate of Plk1. Early reports suggested that Cyclin B1 was phosphorylated by Plk1 at Ser133 and Ser147 sites, which located within cytoplasmic retention signal (CRS) and nuclear-export signal (NES), respectively, for facilitating the translocation of Cyclin B1 to the nucleus during prophase, therein, activating the activity of Cdk1/Cyclin B1 complex and promoting $\mathrm{G}_{2} / \mathrm{M}$ phase transition in vertebrate cells (Table 1) (Toyoshima-Morimoto et al., 2001; Yuan et al., 2002). However, a subsequent study found that the preferential phosphorylation of Plk1 at Ser133 site of Cyclin B1 occurred and is activated on centrosomes, but did not cause the nucleocytoplasmic distribution of Cyclin B1 during prophase (Jackman et al., 2003). Although the discrepancy exists among these reports, the notion of Plk1 phosphorylated activation of Cdc25 and Cyclin B1 and phosphorylated inhibition of Myt1/Wee1 to activate the activity of Cdk1/Cyclin B1 for promoting mitotic entry cooperatively is evident.

In metaphase, Plk1 is recruited by several proteins, including the polo-box interacting protein (PBIP1), the inner centromere protein (INCENP), the spindle checkpoint component BubR1, and the mitotic checkpoint kinase (Bub1) to kinetochores/centromeres to perform its functions at these sites (Fig. 1B; Table 1) (Goto et al., 2006; Kang et al., 2006; Qi et al., 2006; Elowe et al., 2007). In early mitosis, PBIP1 is targeted by Plk1 phosphorylation for degradation (Kang et al., 2006). So the other partners might contribute to localization of Plk1 at kinetochores during mitosis (Petronczki et al., 2008). For example, Bub1 is recognized by PBD of Plk1 once Bub1 has been 'primed' by Cdk1 (Qi, et al., 2006), INCENP and MCAK also shared the similar mechanism to target Plk1 at kinetochores (Goto et al., 2006; Rosasco-Nitcher et al., 2008). In addition, NudC is another partner for recruitment of Plk1 to kinetochores (Nishino et al., 2006). It has been shown that NudC bound to Plk1 and was phosphorylated by Plk1 at Ser274 and Ser326 sites (Table 1) (Zhou et al., 2003).
Plk1-phosphoryated NudC recruits Plk1 to the outer plate of the kinetochores. Kinetochore-targeted Plk1 stimulates the kinetochore recruitment of CENP-E, which promotes stable end-on microtubule-kinetochore interactions and proper congression of chromosomes to the metaphase plate. Depletion of NudC reduced end-on microtubule attachments at kinetochores and resulted in the defects in chromosome congression at the metaphase plate (Nishino et al., 2006). Finally, the observation that the level of Plk1 is particularly high on the kinetochores of those chromosomes that have not yet been attached to both poles of the mitotic spindle and are not under tension (Ahonen et al., 2005; Lénárt et al., 2007) suggests that Plk1 might play critical roles in promoting kinetochore attachment or in spindle checkpoint regulation (Petronczki et al., 2008).

In late mitosis, Plk1 meditates the activity of APC/C, an E3 ubiquitin ligase, which is responsible for timely degradation of various mitotic regulators, to regulate chromosome segregation, exit from mitosis, and a stable subsequent $G_{1}$ phase (Fig. 1B) (Wäsch and Engelbert, 2005). The APC/C complex is first activated by the protein $\mathrm{Cdc} 20$, targeting proteins containing a destruction box ( $D$ box), like Securin. Cdc20 is then degraded and replaced by Cdh1 when the mitotic exit is initiated by $\mathrm{APC} / \mathrm{C}^{\mathrm{Cdc20}}$, thus, allowing the degradation of a wider spectrum of substrates (Eckerdt and Strebhardt, 2006). Emi1 is a major APC/C inhibitor in mitotic cells. At late stage of mitosis, Emi1 is phosphorylated by priming kinase, Cdk1/ Cyclin B1, and then phosphorylated by Plk1, resulting in increased binding of Emi1 to the Skp1-Cullin-F-box ${ }^{\beta-T R C P}$ $\left(\mathrm{SCF}^{\beta-T R C P}\right)$ ubiquitin ligase complex (Table 1) (Eckerdt and Strebhardt, 2006; Martin and Strebhardt, 2006). This leads to the destruction of Emi1 and release of APC/C from inhibition, thus promoting the mitotic exit. Moreover, once there are unfavorable signals originated from kinetochores, Plk1 activates spindle checkpoint signaling pathway to prevent the pre-matured activation of APC/C, which promotes mitosis exit, by indirectly targeting Cdc20 to inhibit APC/C activity (Eckerdt and Strebhardt, 2006). Plk1 phosphorylates 3F3/2 epitope that is recognized by $3 F 3 / 2$ antibody at kinetochores which are not under tension to generate tension-sensing 3F3/2 phosphoepitope (Ahonen et al., 2005; Wong and Fang, 2005). During this process, Plk1 recruits checkpoint protein Mad2 to kinetochores. Also, unattached kinetochores control spindle checkpoint by activating the activity of the checkpoint kinase, BubR1. Activation of BubR1 recruits heterodimer Mad1-Mad2 and activates Mad2. Activated Mad2 and/or BubR1 interact with $\mathrm{Cdc} 20$ and inhibit $\mathrm{Cdc} 20$ to prevent the activation of APC/C activity.

In cytokinesis, Plk1 controls cleavage furrow formation in mammalian cells (Fig. 1B; Table 1). Cytokinesis has to be tightly regulated in both time and space so that the cytoplasm is only divided after chromosome segregation has occurred and only in between the two sets of segregated chromatids (Barr and Gruneberg, 2007). Mitotic spindle plays important 
roles in determining the cleavage plane. Bundled arrays of overlapping antiparallel microtubules form a structure between the two sets of segregated sister chromatids referred to as spindle midzone. The key component of the midzone is called centralspindlin, composed of two molecules of the kinesin Mklp1 and two molecules of HsCyk-4 (RhoGAP) (Pavicic-Kaltenbrunner et al., 2007). At the anaphase, HsCyk-4 binds to Rho guanine-nucleotide exchange factor (RhoGEF) Ect2 and thereby recruits Ect2 to the midzone (Somers and Saint, 2003; Yüce et al., 2005; Zhao and Fang, 2005; Nishimura and Yonemura, 2006). This interaction is thought to enhance the activity of Ect2 and further activate the RhoA, whose activation at equatorial cortex controls the assembly and ingression of the contractile ring by inducing the activity of myosin $\|$ and the polymerization of actin (Petronczki et al., 2008). In this process, Plk1 phosphorylation events play critical roles in regulating the activity of cytokinesis regulators. A microtubule binding protein, Prc1, acting as a Plk1 docking site, recruits Plk1 to spindle midzone by Plk1 'self-priming' phosphorylation of Prc1 at Thr602 (Table 1) (Neef et al., 2007). Plk1 is recruited to the spindle midzone and therein phosphorylates HsCyk-4 at Ser149, 157, 164, 170, 214, and 260 sites (Table 1), consequently generating a recognition site for BRCT domain of Ect2, which contains a phosphor-peptide binding motif (Manke et al., 2003). Binding of Ect2 to HsCyk-4 results in recruitment and activation of Ect2, thereby activating RhoA and initiating the cytokinesis.

\section{NOVEL FUNCTION OF PLK1 IN DNA REPLICATION}

Prior to mitotic entry of cell cycle, DNA must be strictly replicated to maintain the genome integrity of cells. During DNA replication, the replication fork is strictly monitored by a regulation network to ensure the completion of entire genome replication. Defects of the replication fork assembly and monitoring proteins lead to genomic instability, thus resulting in carcinogenesis or a series of diseases known as the 'chromosome instability syndrome (Masai et al., 2010).' In this section, we couldn't cover every aspects of DNA replication due to space limitation, and will mainly focus on the novel function of Plk1, which involves in the assembly and regulation of pre-replicative complex (pre-RC) for facilitating DNA replication under stressful conditions (Fig. 2; Table 1) (Wu and Liu, 2008; Song et al., 2011).

The initiation of DNA replication in eukaryotic cells is a precisely regulated event. From late $M$ phase to early $G_{1}$ phase, an ordered assembly of pre-RC at replicative origins is required for initiation of DNA replication (Fig. 2) (Bell and Dutta, 2002; Blow and Dutta, 2005). The first complex recruited to origins is Origin Recognition Complex (ORC), which contains six subunits (Orc1-6). The ORC, which was first discovered in budding yeast (Bell and Stillman, 1992; Bell and Dutta, 2002), is an ATP-regulated DNA binding protein complex. In mammalian cells, Orc2 to 5 form a stable core complex, while Orc1 and Orc6 are weakly interacted with the core complex (Giordano-Coltart et al., 2005). The ATP-bound ORC binds to origin DNA, followed by subsequent recruitment of Cdc6, licensing factor Cdt1, and Hbo1 (Fig. 2). Mcm2-7 helicase, which is essential for DNA unwinding prior to DNA replication (Liang et al., 1995), is then recruited to the ORC complex. Therein ATP is hydrolyzed and induces the dissociation of Cdc6 and Cdt1 from the ORC, resulting in the stable binding of the MCM with origin DNA.

Going beyond the well-characterized Plk1 functions in mitosis and cytokinesis, recent studies unveil a novel role of PIk1 in S phase. It has been reported that depletion of Plk1 by RNAi resulted in the disruption of pre-RC formation and DNA synthesis reduction in the first cell cycle. This indicates that Plk1 is indeed required for DNA replication in S phase (Yim and Erikson, 2009). Another study showed that Plk1 physically interacted with pre-RC proteins and thereby they were co-localized on centrosomes (Tsvetkov and Stern, 2005; Stuermer et al., 2007), further suggesting a possible role of Plk1 in $S$ phase. To search for direct evidence that Plk1-associated kinase activity might regulate DNA replication, our lab identified two members of DNA replication machinery as Plk1 substrates recently. Aforementioned Hbo1 (histone acetyltransferase binding to the origin recognition complex 1), a binding partner of the Orc1 protein (lizuka and Stillman, 1999), was one of such protein (Wu and Liu, 2008). $\mathrm{Hbo1}$ binds to Mcm2, functioning as a coactivator of Cdt1 for facilitating the loading of MCM complex (Fig. 2). Plk1 directly interacts with $\mathrm{Hbo} 1$ in mitosis and phosphorylates $\mathrm{Hbo} 1$ at Ser57 in vitro and in vivo (Table 1). During mitosis, Hbo1 is first phosphorylated at Thr85/88 by Cdk1 to generate a docking site for subsequent recruitment of Plk1. Overexpression of the Plk1 unphosphorylatable mutant (Hbo1-S57A) leads to a $G_{1} / S$ phase arrest, MCM loading inhibition, and DNA replication reduction. Similarly, $\mathrm{Hbo} 1$ depletion results in decreased DNA replication and a failure of MCM complex binding to chromatin. Significantly, both phenotypes can be partially rescued by the ectopic expression of WT Hbo1 but not Hbo1-S57A, suggesting that Plk1 phosphorylation of $\mathrm{Hbo1}$ is indeed required for pre-RC formation and DNA replication licensing (Wu and Liu, 2008). This is the first piece of direct evidence to support a notion that Plk1 acts as a link to coordinate mitotic events with DNA replication.

Orc2 (origin recognition complex 2), another novel Plk1 substrate recently described, also has a well-documented role in DNA replication (Table 1) (Song et al., 2011). Plk1 was shown to interact with Orc2 in S phase and phosphorylates Orc2 at Ser188 in vitro and in vivo. Strikingly, Orc2-Ser188 phosphorylation is significantly enhanced when DNA replication is under various stresses, including UV, hydroxyurea, gemicitabine, or aphidicolin treatments. Overexpression of Plk1 unphosphorylatable mutant Orc2-S188A leads to defects in DNA synthesis under stress, suggesting that this phosphorylation event is critical to maintain DNA replication 
under stressful conditions. In line with this observation, mechanistic dissection of the role of Plk1 phosphorylation of Orc2 in DNA replication under stress reveals that Orc2 phosphorylated at Ser188 associates with DNA replication origins and the Orc2-S188A mutant fails to maintain the functional pre-RC under replication stress (Fig. 2). Consequently, expression of the Orc2-S188A mutant results in intra-S phase checkpoint activation and delay of S-phase progression. This study suggests a novel role of Plk1 in facilitating DNA replication and maintaining genomic integrity under stressful conditions (Song et al., 2011).

This intriguing finding is reminiscent of us the functions of Plk1 in DNA checkpoint adaption discovered in yeast ( $S$. cerevasiae). In response to DNA damage-induced cell cycle arrest in $G_{2}$, cells will undergo three possible scenarios. First, cells reenter cell cycle after a complete repair of the damaged DNA (checkpoint recovery). Second, apoptosis allows the elimination of cells with unrepaired DNA. Third, cells continue to the cell cycle with damaged DNA (checkpoint adaptation), which is potentially deleterious for cell survival (Bahassi, 2011). In interphase, when DNA damage occurs under stressful conditions, cell cycle is arrested and ATM/ATR-mediated checkpoint signaling pathway is activated, therefore providing time for DNA repair prior to the onset of mitosis (Fig. 2). After DNA repair is complete, Plk1-associated kinase activity mediates the checkpoint recovery for the progression of ongoing cell cycle. However, a mechanism for 'adaptation' to the $G_{2} / M$ DNA damage checkpoint and overriding the checkpoint that permits cells with irreparable damage to reenter the cell cycle was found in yeast ( $S$. cerevasiae) (Shirayama et al., 1998). This mechanism may be beneficial for unicellular organisms because it provides opportunities for cells to repair the damaged chromosomes in the next cell cycle, thus, enhancing their chances for survival (Galgoczy and Toczyski, 2001; Lee et al., 2001). This checkpoint adaption was later shown to be mainly mediated by yeast Plk, Cdc5 (Toczyski et al., 1997). In Xenopus, a similar scenario was observed. Nuclei containing egg extracts with replication inhibitor aphidicolin can adapt to replication stress and enter into mitosis with unreplicated DNA (Yoo et al., 2004). How does Plk1 regulate the inactivation of DNA damage checkpoint and reenter mitosis under stressful conditions? $\mathrm{Plx}$, a Xenopus homolog of Plk1, was shown to inactivate Chk1 by regulating Claspin (Yoo et al., 2004). Claspin is an adaptor protein that is essential for Chk1 activation (Kumagai and Dunphy, 2003). Under genotoxic stress, Claspin is highly phosphorylated in an ATR-dependent manner, and it appears to be necessary for activation of Chk1 by ATR (Kumagai and Dunphy, 2003). However, ATR phosphorylation of Claspin at Thr906 creates a docking site for Plx binding, and the recruited Plx further phosphorylates Claspin at Ser934. Plk1 phosphorylation of Claspin leads to dissociation of Claspin from chromatin, resulting in inactivation of Chk1 and mitotic reentry.
Although checkpoint adaptation in $X$. laevis and $S$. cerevisiae is well-established, whether the similar mechanism exists in mammalian system is still controversial. Adaptation would appear to be unfavorable for mammalian systems because of the obvious mutator effect and the enhanced risk of cancer (Bahassi, 2011). However, Syljuåsen et al. (2006) showed that, following ionizing radiation-induced $G_{2}$ checkpoint arrest, human osteosarcoma cells can enter mitosis with $\gamma-\mathrm{H} 2 \mathrm{AX}$ foci, a marker for unpaired DNA DSBs (double-strand breaks). Plk1 and Chk1 seem to control this process, at least partially, via independent signal pathways. Inhibition of Chk1 promotes exit from $\mathrm{G}_{2}$ checkpoint, whereas overexpression of Chk1 or depletion of Plk1 delays this process. These results suggest that human cells are able to exit the checkpoint arrest and divide before damage has been fully repaired. In line with this notion, under DNA replication stressful conditions, the enhancement of Plk1 phosphorylation of Orc2 was shown to maintain the pre-RC and promote DNA replication at $S$ phase in human cells, albeit intra-S phase checkpoint activation in the Orc2-S188A mutant-expressing cells would delay the progression of cell cycle. Although it is still not known whether the mammalian cells can actually enter mitosis and finish cell division with unrepaired DNA damage that was introduced in S phase, nevertheless, this finding provides additional evidence to support possible existence of checkpoint adaptation mechanism in human cells. Still, it is somewhat surprising that this process occurs in higher eukaryotes, as cell division with damaged DNA may be detrimental for genomic stability and enhances the risk of cancer development (Syljuåsen et al., 2006). It will be very intriguing to speculate that checkpoint adaptation might occur only in cancer cells, but not in normal cells. Further investigation needs to be done to provide more convincing evidence to support this model in mammalian cells.

\section{PLK1 IS ESSENTIAL FOR EARLY EMBRYONIC DEVELOPMENT}

Although much work has focused on Plk1 in cell cycle regulation, little is known about the physiological functions of Plk1 in vivo. In a recent study, Lu and colleagues generated knockout mice to investigate the functions of Plk1 in vivo. Plk1 homozygous null mice were embryonic lethality, and early Plk $1^{-1-}$ embryos failed to survive after the eight-cell stage. However, Plk1 $1^{+/-}$mice are born and fertile, with no obvious effects except a slight decrease in Plk1 levels by comparison with those in Plk1 WT mice. Surprisingly, the increased incidence of tumors in Plk1 heterozygous mice is highly significant by comparing with Plk1 WT mice (Plk $1^{+/-}$ $27.5 \%$ vs Plk1 WT 9\%). This data suggests that Plk1 is important for early embryonic development and may function as a haploinsufficient tumor suppressor (Lu et al., 2008). Moreover, Plk1 also was shown to be very critical for mitosis in the embryonic development of zebrafish. In the early embryonic 
development of zebrafish, the expression of Plk1 was ubiquitous by the bud stage, but became restricted to the proliferating tissues, such as brain, eyes, spinal cord, somites, fin folds, and tail bud, by $24 \mathrm{~h}$ post fertilization. Depletion of Plk1 resulted in mitotic arrest and finally death by 6 days post-fertilization (Jeong et al., 2010). Taken together, these studies suggest that Plk1 is essential for early embryonic development and normal level of Plk1 is critical for maintaining chromosomal stability. Deregulation of Plk1 in embryonic development leads to embryonic lethality or increased risk of tumorigenesis in development.

\section{DEREGULATION OF PLK1 LEADS TO ONCOGENIC TRANSFORMATION}

In normal cells, the expression level and activity of Plk1 is strictly controlled by its upstream regulators and proteasomal degradation, respectively, for orderly regulating cell cycle events. The expression and activity of Plk1 is low throughout $G_{0}, G_{1}$, and $S$ phase, begins to rise in $G_{2}$ phase and peaks during $M$ phase (Lake and Jelinek, 1993; Golsteyn et al., 1994, 1995; Lee et al., 1995). Plk1 is then degraded by the APC/C starting in late mitosis and continuing throughout $G_{1}$. In many cancer cell lines, Plk1 can be easily detected in $\mathrm{G}_{1}$ phase with apparent nuclear localization ( $\mathrm{Li}$ et al., 2008). Deregulated activity of Plk1 results in abnormalities in centrosome duplication, maturation and/or microtubule dynamics, therefore causing increased centrosome size and/or centrosome number, both of which show a positive and significant correlation with aneuploidy and chromosomal instability (Takai et al., 2005). Therefore, Plk1 has been accepted as a marker for cell proliferation and associates with oncogenic transformation. A well-known study shows overexpression of murine Plk1 in NIH3T3 cells led to a transformed phenotype. The transformed cells formed colonies and were capable of growth in soft agar and formation of tumors in nude mice (Smith et al., 1997). Furthermore, it has been reported that elevated levels of Plk1 were found in non-small-cell lung cancer (Wolf et al., 1997), head/neck squamous cell carcinomas (HNSCC) (Knecht et al., 1999), esophageal carcinoma (Tokumitsu et al., 1999), oropharyngeal carcinomas (Knecht et al., 2000), melanomas (Strebhardt et al., 2000), breast cancer (Wolf et al., 2000), endometrial carcinomas (Takai et al., 2001b), colorectal cancer (Macmillan et al., 2001; Takahashi et al., 2003), ovarian cancer (Takai et al., 2001a; Weichert et al., 2004a), pancreatic cancer (Gray et al., 2004), prostate carcinomas (Weichert et al., 2004b) and in papillary carcinomas (Ito et al., 2004). These studies suggest that deregulation of Plk1 highly correlates with carcinogenesis of various tumors in human.

\section{Possible roles of Plk1 in prostate cancer development}

Prostate cancer is the most common cancer in Western men and the leading cause of cancer deaths in the United States. Although we still could not fully understand the mechanisms of prostate cancer initiation and progression, recent advances in high throughput genetic technologies together with various animal model studies and human tissues of prostate cancer allow a comprehensive analysis and functional validation of the molecular changes, therefore identifying critical genetic and epigenetic changes that promote prostate cancer initiation and progression, and developing novel therapeutic approaches that can help to combat this disease (Knudsen and Vasioukhin, 2010).

\section{Architecture of prostate gland}

Human prostate gland, which surrounds the urethra, is resided at the base of the bladder. It is a walnut-sized organ. Adult prostate gland lacks discernible lobular structures. McNeal defined the human prostate as a zonal structure, including central zone, peripheral zone, transition zone, and anterior fibromuscular zone (Fig. 3A) (McNeal, 1969, 1981, 1988; Timms, 2008). It is worthy to note that the outmost peripheral zone occupies the most volume of the prostate and is the carrier of the majority of malignant prostate carcinomas, whereas the benign prostatic hyperplasia (BPH), a common non-malignant tumor, arises from the transition zone (Fig. 3A and 3B) (Shen and Abate-Shen, 2010). In contrast to human prostate, mouse prostate gland is composed of several distinct lobular structures, including ventral, lateral, dorsal, and anterior lobes (Fig. 3A). The dorsolateral lobe of mouse prostate gland is most similar to the peripheral zone of those in human by comparison of the gene expression profiling of human and mouse prostate gland (Berquin et al., 2005).

Both human and mouse prostate glands consist of two compartments: epithelial and stromal (Fig. 3B). And these two compartments are separated by basement membrane, which is the packed structure of collagen fibers containing various extracellular proteins secreted from both epithelial and stromal cells (Bonkhoff et al., 1991, 1992). The epithelial layers contain three differentiated cell types: luminal, basal, and neuroendocrine (Fig. 3B) (Foster et al., 2002; van Leenders and Schalken, 2003; Hudson, 2004; Shappell et al., 2004; Peehl, 2005). The polarized columnar epithelial cells form a continuous layer, luminal layer, which is responsible for the prostatic secretions. Luminal cells express high levels of androgen receptor (AR), cytokeratin 8/18, CD57, and

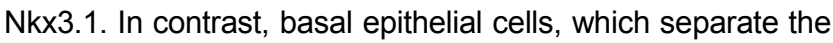
luminal layer from stroma (Brawer et al., 1985; Nagle et al., 1987; Liu et al., 1997; van Leenders and Schalken, 2003), express cytokeratins 5/14, P63, CD44, GSTP1, with low or undetectable levels of AR (Knudsen and Vasioukhin, 2010; Shen and Abate-Shen, 2010). Neuroendocrine cells, which are morphologically indistinguishable from basal cells, express endocrine markers, such as Chromgranin $A$ and synaptophysin, but do not express AR (Shen and Abate-Shen, 
A

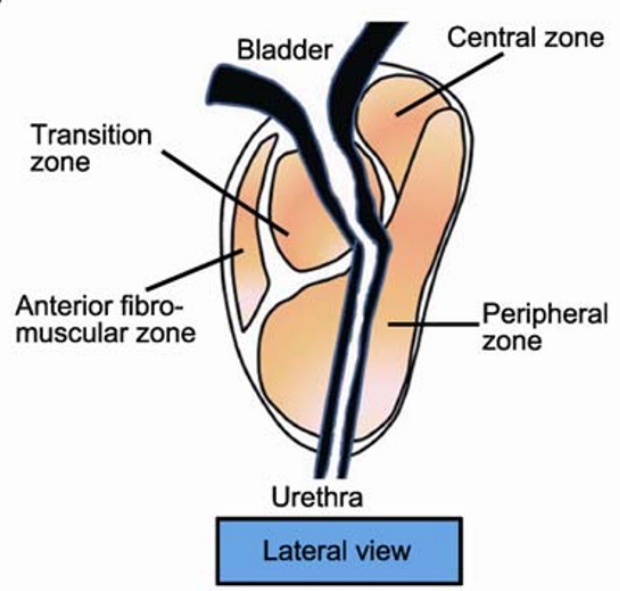

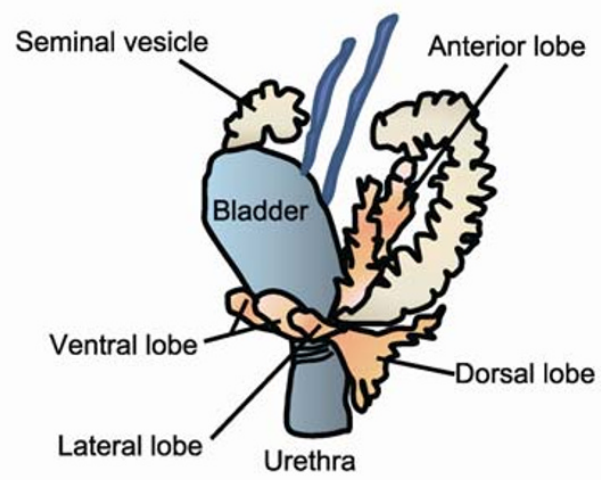

Lateral view

B

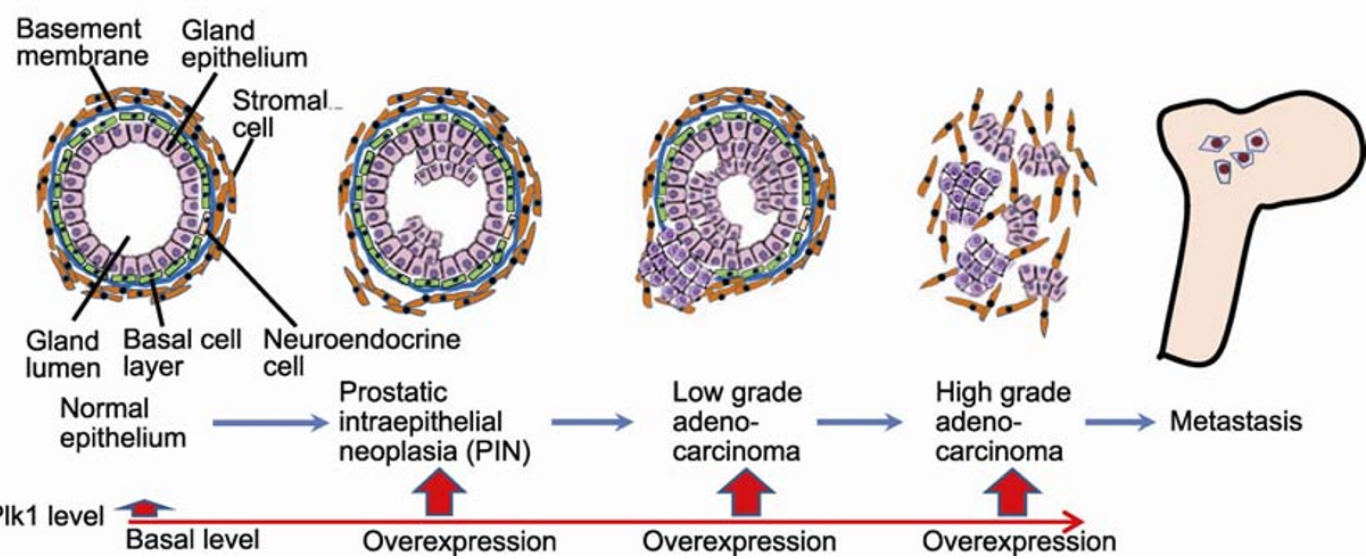

Figure 3. The comparison of the architectures of human and mouse prostate glands (A) and model of histological changes during prostate cancer initiation and progression (B). It has been shown that the overexpression of Plk1 in each stage of prostate carcinoma of tissue specimens by comparing with normal prostate tissues (Weichert et al., 2004b) (bottom panel).

2010). Cell type specific expression is often used to analyze the prostate gland and to detect glandular pathology (Shen and Abate-Shen, 2010). The stromal cell compartment of prostate gland contains several different cell types, including smooth muscle cells, fibroblasts, and endothelial cells with smooth muscle cells as the most abundant cell type (Bartsch et al., 1979).

\section{Overexpression of Plk1 in prostate cancer development}

Advanced age is the most highly risk factor for prostate cancer initiation. It has been reported that men who are younger than 40 have one in 10,000 chance of developing prostate cancer and that the risk increases to one in seven by the age of 60 (American Cancer Society, 2009). However, prostate cancer is not simply a by-product of aging, since incidence varies considerably among different populations (Shen and Abate-Shen, 2010). This phenomenon more likely reflects the interplay of environmental, physiological, and molecular influences with normal consequences of aging that presumably exacerbate the effects of these influences (Shen and Abate-Shen, 2010). The development of human prostate cancer includes four stages, which develops from prostatic intraepithelial neoplasia (PIN) to high grade adenocarcinoma, and then metastasis (Fig. 3B). Several important factors which have been implicated in prostate cancer initiation and progression, including inflammation, oxidative stress and DNA damage, telomere shortening, senescence, genomic alterations, genetic factors, and epigenetic alterations, together with molecular mechanisms of prostate carcinogenesis, have been subjected to extensive reviews (Knudsen and Vasioukhin, 2010; Shen and Abate-Shen, 2010). We here pay more attention to our lab's recent finding on the role of Plk1 in prostate cancer initiation.

It has been shown that Plk1 associates with prostate cancer initiation and progression. In the study by Weichert 
and his colleagues, 78 tissue specimens of human prostate carcinoma, adjacent normal prostate tissue, and benign hyperplasia, were used to investigate the expression of Plk1. It was shown that $52.6 \%$ of prostate cancer specimens had strong expression of Plk1 and that expression of Plk1 positively correlated with Gleason grade (Fig. 3B) (Weichert et al., 2004b). In contrast, no significant Plk1 expression was detected in normal prostate epithelium and stroma as well as in the benign prostate hyperplasia specimens. This study demonstrated that Plk1 is overexpressed in prostate cancer and is linked to higher tumor grades (Weichert et al., 2004b). Moreover, knockdown of Plk1 by RNAi resulted in a significant decrease in cell viability, induction of apoptosis, defects in important mitotic processes (failure of cytokinesis, and the defects in centrosome integrity and maturation), and $G_{2} / M$ phase arrest in human prostate cancer cell lines representing different stages of disease progression (Reagan-Shaw and Ahmad, 2005b). Although the link between Plk1 and prostate cancer was well-established in these studies, the mechanism underlying the role of Plk1 in prostate cancer initiation and progression remains elusive. In a recent publication, Liu and colleagues unveiled the mechanism of Plk1 in facilitating loss of Pten-induced prostate cancer formation. In this report, prostate cancer cell lines, prostate-specific Pten-deletion mouse model, xenograft mouse model were used to investigate the role of Plk1 in loss of Pten-induced prostate cancer. Pten knockout study showed that depletion of Pten results in an elevated level of Plk1 in Pten ${ }^{-1-}$ mouse prostate tissues and that the elevation of Plk1 is critical for Pten-depleted cells to adapt to mitotic stress, which is conferred by Pten depletion, for survival. Moreover, overexpression of Plk1 correlates with genetic inactivation of Pten during human prostate neoplasia formation (Liu et al., 2011). Prostate cancer is associated with genetic alterations involving the PI3K and AR pathways, both of which mediate survival signals in prostate cancer (Carver et al., 2011). About $40 \%$ of primary and $70 \%$ of metastatic prostate cancers have genetic alterations in the PI3K pathway, mostly through loss of Pten (El Sheikh et al., 2008; Reid et al., 2010; Taylor et al., 2010). Studies based on conditional prostate-specific Pten deletion and Pten silenced cell lines have established that loss of Pten promotes resistance to castration (Gao et al., 2006; Jiao et al., 2007), suggesting that loss of Pten might be one of the causes of the development of castration resistance prostate cancer (CRPC). Furthermore, it is most likely that Plk1 mediates the Pten loss after castration, therefore resulting in the development of CRPC. It will be very intriguing to test whether Plk1 directly targets Pten and causes its inactivation. Nevertheless, this finding sheds light on further dissection of the mechanism of Plk1 in prostate cancer initiation and progression.

\section{Targeting Plk1 in prostate cancer treatment}

It is well-characterized that Plk1 is a key player in cell prolif- eration and that overexpression of Plk1 contributes to oncogenic transformation (Guan et al., 2005). A study of overexpression of Plk1 in NIH3T3 cells which confers the transformed phenotype (Eckerdt et al., 2005) suggested that Plk1 overexpression is a cause but not a result of oncogenic transformation (Ahmad, 2004; Spänkuch et al., 2004; Eckerdt et al., 2005; Reagan-Shaw and Ahmad, 2005a). So inhibition of Plk1 might become a promising new chemotherapeutic approach for prostate cancer treatment (Weichert et al., 2004b). Depletion of Plk1 by siRNA resulted in induction of apoptosis of human cancer cells (Liu and Erikson, 2003). In a further detailed study, knockdown of Plk1 in three prostate cancer cell lines, LNCaP, DU145, and PC-3, by siRNA approach also resulted in a significant decrease in growth and viability with concurrent induction of apoptosis (Reagan-Shaw and Ahmad, 2005b). Therefore, Plk1 has been proposed as a promising drug target for prostate cancer treatment (Reagan-Shaw and Ahmad, 2005a). Indeed, numerous small-molecule Plk inhibitors have been developed to target ATP-binding pocket and PBD domain of Plk1, respectively. However, because of the high level of sequence identity of kinase domain of Plk1 with those of Plk2, Plk3, and Plk4, ATP-competitive inhibitors of Plk1, such as PHA-680626 and BI2536, scarcely discriminate between Plk1 and Plk3 (Kothe et al., 2007a, 2007b; Steegmaier et al., 2007). Therefore, the development of specific ATP-competitive Plk1 inhibitors is still challenging (Johnson et al., 2007). Targeting the PBD of PIk1 is another strategy for developing Plk1 inhibitors. Recently, small molecule inhibitors for impairing the interaction of Plk1 PBD with its substrates were identified with a high-throughput screening assay based on fluorescence polarization (Reindl et al., 2008a, 2008b). Some specific PBD inhibitors, such as poloxin (Hanisch et al., 2006), poloxipan (Reindl et al., 2009), and purpurogallin (Watanabe et al., 2009), were identified and their antitumor activity were under investigation. In addition, several other Plk1 inhibitors, including BI2536, BI6727, ON01910.Na, HMN-214, GW843682X, GSK461364, NMSP937, have been developed to evaluate their potential in cancer treatments clinically (Strebhardt, 2010).

\section{CLINICAL-TRANSLATIONAL TRIALS OF PLK INHIBITORS}

The aforementioned Plk1 inhibitors have been investigated in clinical trials. The results from phase I or II studies of four Plk1 inhibitors, BI2536, ON01910.Na, HMN-214, and GSK461364, have been reported recently (Garland et al., 2006; Jimeno et al., 2008; Mross et al., 2008; Pandha et al., 2008; Sehnoy et al., 2008; Vose et al., 2008; Gandhi et al., 2009; Olmos et al., 2009; Sebastian et al., 2009).

BI2536, a highly selective ATP-competitive Plk1 inhibitor, causes perturbation of the spindle assembly, resulting in mitotic arrest and apoptosis. BI2536 has been studied in patients with solid tumors or hematologic malignancies. In 
phase I trials, various dose-ranging schedules were used to assess the maximum-tolerated dose (MTD), overall safety, pharmacokinetics (PK), and efficacy of i.v. BI2536. The MTD of $175 \mathrm{mg}$ or $200 \mathrm{mg}$ was established for the patients with relapsed or refractory non-Hodgkin's lymphoma (NHL), or advanced solid tumors, respectively, when administered every 21 days. Nausea, fatigue, and anorexia were of moderate to mild intensity (Mross et al., 2008; Vose et al., 2008). Phase II studies of BI2536 in patients with non-small lung cancer and hormone refractory prostate cancer showed modest activity. Mild fatigue and nausea were also observed (Pandha et al., 2008; Sebastian et al., 2009).

ON01910.Na has been shown to inhibit the growth of cancer cells and lead to the apoptosis in multiple cancer cell lines in vitro and in vivo (Gumireddy et al., 2005). The treatment of the cells with ON01910.Na resulted in abnormalities of spindle and centrosomes and cell cycle arrest at $\mathrm{G}_{2} / \mathrm{M}$ phase. In phase I trials, the MTD of $3120 \mathrm{mg}$ of ON01910.Na was established when administered in 4-week cycles (2-h infusion, twice weekly for 3 weeks). The common adverse events, including fatigue, pain, nausea, vomiting, and abdominal pain, were observed (Jimeno et al., 2008).

HMN-214 is an oral stilbene derivative and is a prodrug of the active agent $\mathrm{HMN}-176$. HMN-176 interferes with the subcellular localization of Plk1, resulting in $\mathrm{G}_{2} / \mathrm{M}$ arrest and destruction of the spindle polar bodies and DNA fragmentation. Two phase I studies in patients with advanced solid tumors were performed to assess the MTD and the pharmacokinetics of $\mathrm{HMN}-214$. An MTD of $8 \mathrm{mg} / \mathrm{m}^{2} / \mathrm{d}$ was established when administered orally, daily for 21 days of a 28-day cycle. Severe myalgia and/or bone pain syndrome and hyperglycemia with dose-limiting toxicity (DLTs) at a dose of $9.9 \mathrm{mg} / \mathrm{m}^{2} / \mathrm{d}$ were observed in this dosing schedule. In 5-day dosing schedule, the DLTs, neutropenic sepsis and prolonged neutropenia were observed in the heavily pretreated patients, while DLTs were febrile neutropenia, electrolyte disturbances, neuropathy, and myalgia in lightly pretreated patients (Patnaik et al., 2003; von Hoff et al., 2004; Garland et al., 2006).

GSK461364 is a selective i.v. thiophene amide ATP-competitive inhibitor of Plk1. High concentration ( $>300$ $\mathrm{nmol} / \mathrm{L}$ ) of GSK461364 caused $\mathrm{G}_{2}$ phase arrest and low concentration (10-300 nmol/L) caused $M$ phase arrest. In phase I studies, an MTD of $225 \mathrm{mg}$ was established when administered weekly for 3 weeks in a 4-week cycle, while the MTD was $75 \mathrm{mg}$ when administered twice weekly for 3 weeks in 4-week cycle. The observed DLTs were neutropenia, thrombocytopenia, and bone marrow suppression (Olmos et al., 2009).

\section{FURTHER PERSPECTIVES-PLK1 RISES FROM CELL CYCLE REGULATION TO CANCER RESEARCH}

There is no doubt that great advances have been made in elucidating the roles of Plk1 in cell cycle regulation over the past 20 years. These advances have greatly improved our understanding of how Plk1 works in mediating many cell cycle events, including DNA replication, centrosome maturation, bipolar spindle formation, cytokinesis, cell cycle checkpoint activation and inactivation by phosphorylation of different specific substrates. Although many studies have linked Plk1 with oncogenic transformation and carcinogenesis, and come out with a wealth of phenotypic information to support the correlation of Plk1 elevation with various cancer initiation and progression, little is known about the 'in-depth' mechanism of Plk1 in carcinogenesis, or at least, in prostate carcinogenesis. In future studies, going beyond the classical cell cycle-related Plk1 functions, identifying new Plk1 partners, and linking Plk1 with oncogenic signaling pathways would be an attractive direction for the next wave of Plk1 research.

\section{ACKNOWLEDGEMENTS}

We would like to thank Bing Song and $X$. Shawn Liu, who provide very convincing data and conclusion for this review writing, and would like to thank all the researchers who have made great contributions to this research area.

\section{ABBREVIATIONS}

$\mathrm{AR}$, androgen receptor; CRS, cytoplasmic retention signal; INCENP, the inner centromere protein; $\gamma$-TuRC, $\gamma$-tubulin ring complexes; MTD, maximum-tolerated dose; NES, nuclear- export signal; NLP, nineinlike protein; ORC, Origin Recognition Complex; PBD, polo-box domains; PBIP1, polo-box interacting protein; Plk1, polo-like kinase 1

\section{REFERENCES}

Ahmad, N. (2004). Polo-like kinase (Plk) 1: a novel target for the treatment of prostate cancer. FASEB J 18, 5-7.

Ahonen, L.J., Kallio, M.J., Daum, J.R., Bolton, M., Manke, I.A., Yaffe, M.B.,Stukenberg, P.T., and Gorbsky, G.J. (2005). Polo-like kinase 1 creates the tension-sensing 3F3/2 phosphoepitope and modulates the association of spindle-checkpoint proteins at kinetochores. Curr Biol 15, 1078-1089.

American Cancer Society. (2009). Cancer facts \& figures 2009. American Cancer Society, Atlanta, GA.

Andrysik, Z., Bernstein, W.Z., Deng, L., Myer, D.L., Li, Y.-Q., Tischfield, J.A., Stambrook, P.J., and Bahassi, M. (2010). The novel mouse Polo-like kinase 5 responds to DNA damage and localizes in the nucleolus. Nucleic Acids Res 38, 2931-2943.

Archambault, V., and Glover, D.M. (2009). Polo-like kinases: conservation and divergence in their functions and regulation. Nat Rev Mol Cell Biol 10, 265-275.

Bahassi el, M. (2011). Polo-like kinases and DNA damage checkpoint: beyond the traditional mitotic functions. Exp Biol Med 236, 648-657.

Barr, F.A., and Gruneberg, U. (2007). Cytokinesis: placing and making the final cut. Cell 131, 847-860.

Barr, F.A., Silljé, H.H., and Nigg, E.A. (2004). Polo-like kinases and the 
orchestration of cell division. Nat Rev Mol Cell Biol 5, 429-440.

Bartsch, G., Frick, J., Rüegg, I., Bucher, M., Holliger, O., Oberholzer, M., and Rohr, H.P. (1979). Electron microscopic stereological analysis of the normal human prostate and of benign prostatic hyperplasia. J Urol 122, 481-486.

Bell, S.P., and Dutta, A. (2002). DNA replication in eukaryotic cells. Annu Rev Biochem 71, 333-374.

Bell, S.P., and Stillman, B. (1992). ATP-dependent recognition of eukaryotic origins of DNA replication by a multiprotein complex. Nature 357, 128-134.

Berquin, I.M., Min, Y., Wu, R., Wu, H., and Chen, Y.Q. (2005). Expression signature of the mouse prostate. J Biol Chem 280, 36442-36451.

Blow, J.J., and Dutta, A. (2005). Preventing re-replication of chromosomal DNA. Nat Rev Mol Cell Biol 6, 476-486.

Bonkhoff, H., Wernert, N., Dhom, G., and Remberger, K. (1991). Basement membranes in fetal, adult normal, hyperplastic and neoplastic human prostate. Virchows Arch A Pathol Anat Histopathol 418, 375-381.

Bonkhoff, H., Wernert, N., Dhom, G., and Remberger, K. (1992). Distribution of basement membranes in primary and metastatic carcinomas of the prostate. Hum Pathol 23, 934-93.

Brawer, M.K., Peehl, D.M., Stamey, T.A., and Bostwick, D.G. (1985). Keratin immunoreactivity in the benign and neoplastic human prostate. Cancer Res 45, 3663-3667.

Burkard, M.E., Maciejowski, J., Rodriguez-Bravo, V., Repka, M., Lowery, D.M., Clauser, K.R., Zhang, C., Shokat, K.M., Carr, S.A., Yaffe, M.B., et al. (2009). Plk1 self-organization and priming phosphorylation of HsCYK-4 at the spindle midzone regulate the onset of division in human cells. PLoS Biol 7, e1000111.

Carver, B.S., Chapinski, C., Wongvipat, J., Hieronymus, H., Chen, Y., Chandarlapaty, S., Arora, V.K., Le, C., Koutcher, J., Scher, H., et al. (2011). Reciprocal feedback regulation of PI3K and androgen receptor signaling in PTEN-deficient prostate cancer. Cancer Cell 19, 575-586.

Casenghi, M., Barr, F.A., and Nigg, E.A. (2005). Phosphorylation of Nlp by Plk1 negatively regulates its dynein-dynactin-dependent targeting to the centrosome. J Cell Sci 118, 5101-5108.

Casenghi, M., Meraldi, P., Weinhart, U., Duncan, P.I., Körner, R., and Nigg, E.A. (2003). Polo-like kinase 1 regulates NIp, a centrosome protein involved in microtubule nucleation. Dev Cell 5, 113-125.

Cheng, K.-Y., Lowe, E.D., Sinclair, J., Nigg, E.A., and Johnson, L.N. (2003). The crystal structure of the human polo-like kinase-1 polo box domain and its phospho-peptide complex. EMBO J 22, 5757-5768.

Clay, F.J., McEwen, S.J., Bertoncello, I., Wilks, A.F., and Dunn, A.R. (1993). Identification and cloning of a protein kinase-encoding mouse gene, Plk, related to the polo gene of Drosophila. Proc Natl Acad Sci U S A 90, 4882-4886.

Eckerdt, F., and Strebhardt, K. (2006). Polo-like kinase 1: target and regulator of anaphase-promoting complex/cyclosome-dependent proteolysis. Cancer Res 66, 6895-6898.

Eckerdt, F., Yuan, J., and Strebhardt, K. (2005). Polo-like kinases and oncogenesis. Oncogene 24, 267-276.

El Sheikh, S.S., Romanska, H.M., Abel, P., Domin, J., and Lalani, N. (2008). Predictive value of PTEN and AR coexpression of sustained responsiveness to hormonal therapy in prostate cancer-a pilot study. Neoplasia 10, 949-953.
Elia, A.E., Cantley, L.C., and Yaffe, M.B. (2003a). Proteomic screen finds pSer/pThr-binding domain localizing Plk1 to mitotic substrates. Science 299, 1228-1231.

Elia, A.E.H., Rellos, P., Haire, L.F., Chao, J.W., Ivins, F.J., Hoepker, K., Mohammad, D., Cantley, L.C., Smerdon, S.J., and Yaffe, M.B. (2003b). The molecular basis for phosphodependent substrate targeting and regulation of Plks by the Polo-box domain. Cell 115, 83-95.

Elowe, S., Hümmer, S., Uldschmid, A., Li, X., and Nigg, E.A. (2007). Tension-sensitive Plk1 phosphorylation on BubR1 regulates the stability of kinetochore microtubule interactions. Genes Dev 21, 2205-2219.

Foster, C.S., Dodson, A., Karavana, V., Smith, P.H., and Ke, Y. (2002). Prostatic stem cells. J Pathol 197, 551-565.

Galgoczy, D.J., and Toczyski, D.P. (2001). Checkpoint adaptation precedes spontaneous and damage-induced genomic instability in yeast. Mol Cell Biol 21, 1710-1718.

Gandhi, L., Chu, Q.S., Stephenson, J., et al. (2009). An open label phase II trial of the Plk1 inhibitor BI 2536, in patients with sensitive relapsed small cell lung cancer (SCLC). J Clin Oncol, 27. [abstract 8108]

Gao, H., Ouyang, X., Banach-Petrosky, W.A., Shen, M.M., and Abate-Shen, C. (2006). Emergence of androgen independence at early stages of prostate cancer progression in Nkx3.1; Pten mice. Cancer Res 66, 7929-7933.

Garland, L.L., Taylor, C., Pilkington, D.L., Cohen, J.L., and Von Hoff, D.D. (2006). A phase I pharmacokinetic study of $\mathrm{HMN}-214$, a novel oral stilbene derivative with polo-like kinase-1-interacting properties, in patients with advanced solid tumors. Clin Cancer Res 12, 5182-5189.

Giordano-Coltart, J., Ying, C.Y., Gautier, J., and Hurwitz, J. (2005). Studies of the properties of human origin recognition complex and its Walker A motif mutants. Proc Natl Acad Sci U S A 102, 69-74.

Glover, D.M., Hagan, I.M., and Tavares, A.A.M. (1998). Polo-like kinases: a team that plays throughout mitosis. Genes Dev 12, 3777-3787.

Golsteyn, R.M., Mundt, K.E., Fry, A.M., and Nigg, E.A. (1995). Cell cycle regulation of the activity and subcellular localization of Plk1, a human protein kinase implicated in mitotic spindle function. $J$ Cell Biol 129, 1617-1628.

Golsteyn, R.M., Schultz, S.J., Bartek, J., Ziemiecki, A., Ried, T., and Nigg, E.A. (1994). Cell cycle analysis and chromosomal localization of human Plk1, a putative homologue of the mitotic kinases Drosophila polo and Saccharomyces cerevisiae Cdc5. J Cell Sci 107, 1509-1517.

Goto, H., Kiyono, T., Tomono, Y., Kawajiri, A., Urano, T., Furukawa, K., Nigg, E.A., and Inagaki, M. (2006). Complex formation of Plk1 and INCENP required for metaphase-anaphase transition. Nat Cell Biol 8, 180-187.

Gray, P.J. Jr, Bearss, D.J., Han, H., Nagle, R., Tsao, M.-S., Dean, N., and Von Hoff, D.D. (2004). Identification of human polo-like kinase 1 as a potential therapeutic target in pancreatic cancer. Mol Cancer Ther 3, 641-646.

Guan, R., Tapang, P., Leverson, J.D., Albert, D., Giranda, V.L., and Luo, Y. (2005). Small interfering RNA-mediated Polo-like kinase 1 depletion preferentially reduces the survival of p53-defective, oncogenic transformed cells and inhibits tumor growth in animals. Cancer Res 65, 2698-2704. 
Gumireddy, K., Reddy, M.V., Cosenza, S.C., Boominathan, R., Baker, S.J., Papathi, N., Jiang, J., Holland, J., and Reddy, E.P. (2005). ON01910, a non-ATP-competitive small molecule inhibitor of Plk1, is a potent anticancer agent. Cancer Cell 7, 275-286.

Hanisch, A., Wehner, A., Nigg, E.A., and Silljé, H.H. (2006). Different Plk1 functions show distinct dependencies on Polo-Box domain-mediated targeting. Mol Biol Cell 17, 448-459.

Hansen, D.V., Loktev, A.V., Ban, K.H., and Jackson, P.K. (2004). Plk1 regulates activation of the anaphase promoting complex by phosphorylating and triggering SCFbetaTrCP-dependent destruction of the APC Inhibitor Emi1. Mol Biol Cell 15, 5623-5634.

Hudson, D.L. (2004). Epithelial stem cells in human prostate growth and disease. Prostate Cancer Prostatic Dis 7, 188-194.

Hudson, J.W., Kozarova, A., Cheung, P., Macmillan, J.C., Swallow, C.J., Cross, J.C., and Dennis, J.W. (2001). Late mitotic failure in mice lacking Sak, a polo-like kinase. Curr Biol 11, 441-446.

lizuka, M., and Stillman, B. (1999). Histone acetyltransferase HBO1 interacts with the ORC1 subunit of the human initiator protein. $J$ Biol Chem 274, 23027-23034.

Inoue, D., and Sagata, N. (2005). The Polo-like kinase Plx1 interacts with and inhibits Myt1 after fertilization of Xenopus eggs. EMBO J 24, 1057-1067.

Ito, Y., Miyoshi, E., Sasaki, N., Kakudo, K., Yoshida, H., Tomoda, C., Uruno, T., Takamura, Y., Miya, A., Kobayashi, K., et al. (2004). Polo-like kinase 1 overexpression is an early event in the progression of papillary carcinoma. Br J Cancer 90, 414-418.

Jackman, M., Lindon, C., Nigg, E.A., and Pines, J. (2003). Active cyclin B1-Cdk1 first appears on centrosomes in prophase. Nat Cell Biol 5, 143-148.

Jeong, K., Jeong, J.Y., Lee, H.O., Choi, E., and Lee, H. (2010). Inhibition of Plk1 induces mitotic infidelity and embryonic growth defects in developing zebrafish embryos. Dev Biol 345, 34-48.

Jiao, J., Wang, S., Qiao, R., Vivanco, I., Watson, P.A., Sawyers, C.L., and $\mathrm{Wu}, \mathrm{H}$. (2007). Murine cell lines derived from Pten null prostate cancer show the critical role of PTEN in hormone refractory prostate cancer development. Cancer Res 67, 6083-6091.

Jimeno, A., Li, J., Messersmith, W.A., Laheru, D., Rudek, M.A., Maniar, M., Hidalgo, M., Baker, S.D., and Donehower, R.C. (2008). Phase I study of ON 01910.Na, a novel modulator of the Polo-like kinase 1 pathway, in adult patients with solid tumors. J Clin Oncol 26, 5504-5510.

Johnson, E.F., Stewart, K.D., Woods, K.W., Giranda, V.L., and Luo, Y. (2007). Pharmacological and functional comparison of the polo-like kinase family: insight into inhibitor and substrate specificity. Biochemistry 46, 9551-9563.

Kang, Y.H., Park, J.-E., Yu, L.-R., Soung, N.-K., Yun, S.-M., Bang, J.K., Seong, Y.-S., Yu, H., Garfield, S., Veenstra, T.D., et al. (2006). Self-regulated Plk1 recruitment to kinetochores by the Plk1-PBIP1 interaction is critical for proper chromosome segregation. Mol Cell 24, 409-422.

Knecht, R., Elez, R., Oechler, M., Solbach, C., von Ilberg, C., and Strebhardt, K. (1999). Prognostic significance of polo-like kinase (PLK) expression in squamous cell carcinomas of the head and neck. Cancer Res 59, 2794-2797.

Knecht, R., Oberhauser, C., and Strebhardt, K. (2000). PLK (polo-like kinase), a new prognostic marker for oropharyngeal carcinomas. Int J Cancer 89, 535-536.

Knudsen, B.S., and Vasioukhin, V. (2010). Mechanisms of prostate cancer initiation and progression. Adv Cancer Res 109, 1-50.

Kothe, M., Kohls, D., Low, S., Coli, R., Cheng, A.C., Jacques, S.L., Johnson, T.L., Lewis, C., Loh, C., Nonomiya, J., et al. (2007a). Structure of the catalytic domain of human polo-like kinase 1. Biochemistry 46, 5960-5971.

Kothe, M., Kohls, D., Low, S., Coli, R., Rennie, G.R., Feru, F., Kuhn, C., and Ding, Y.H. (2007b). Selectivity-determining residues in Plk1. Chem Biol Drug Des 70, 540-546.

Kumagai, A., and Dunphy, W.G. (1996). Purification and molecular cloning of Plx1, a Cdc25-regulatory kinase from Xenopus egg extracts. Science 273, 1377-1380.

Kumagai, A., and Dunphy, W.G. (2003). Repeated phosphopeptide motifs in Claspin mediate the regulated binding of Chk1. Nat Cell Biol 5, 161-165.

Lake, R.J., and Jelinek, W.R. (1993). Cell cycle- and terminal differentiation-associated regulation of the mouse mRNA encoding a conserved mitotic protein kinase. Mol Cell Biol 13, 7793-7801.

Lane, H.A., and Nigg, E.A. (1996). Antibody microinjection reveals an essential role for human polo-like kinase 1 (Plk1) in the functional maturation of mitotic centrosomes. J Cell Biol 135, 1701-1713.

Lee, K.S., Park, J.-E., Kang, Y.H., Zimmerman, W., Soung, N.-K., Seong, Y.-S., Kwak, S.-J., and Erikson, R.L. (2008). Mechanisms of mammalian polo-like kinase 1 (Plk1) localization: self- versus non-self-priming. Cell Cycle 7, 141-145.

Lee, K.S., Yuan, Y.L., Kuriyama, R., and Erikson, R.L. (1995). Plk is an $M$-phase-specific protein kinase and interacts with a kinesin-like protein, CHO1/MKLP-1. Mol Cell Biol 15, 7143-7151.

Lee, S.E., Pellicioli, A., Malkova, A., Foiani, M., and Haber, J.E. (2001). The Saccharomyces recombination protein Tid1p is required for adaptation from G2/M arrest induced by a double-strand break. Curr Biol 11, 1053-1057.

Lénárt, P., Petronczki, M., Steegmaier, M., Di Fiore, B., Lipp, J.J., Hoffmann, M., Rettig, W.J., Kraut, N., and Peters, J.-M. (2007). The small-molecule inhibitor BI 2536 reveals novel insights into mitotic roles of polo-like kinase 1. Curr Biol 17, 304-315.

Li, H., Liu, X.S., Yang, X., Song, B., Wang, Y., and Liu, X. (2010b). Polo-like kinase 1 phosphorylation of $\mathrm{p} 150^{\text {Glued }}$ facilitates nuclear envelope breakdown during prophase. Proc Natl Acad Sci U S A 107, 14633-14638.

Li, H., Liu, X.S., Yang, X., Wang, Y., Wang, Y., Turner, J.R., and Liu, X. (2010a). Phosphorylation of CLIP-170 by Plk1 and CK2 promotes timely formation of kinetochore-microtubule attachments. EMBO J 29, 2953-2965.

Li, H., Wang, Y., and Liu, X. (2008). Plk1-dependent phosphorylation regulates functions of DNA topoisomerase Ilalpha in cell cycle progression. J Biol Chem 283, 6209-6221.

Liang, C., Weinreich, M., and Stillman, B. (1995). ORC and Cdc6p interact and determine the frequency of initiation of DNA replication in the genome. Cell 81, 667-676.

Liu, A.Y., True, L.D., LaTray, L., Nelson, P.S., Ellis, W.J., Vessella, R.L., Lange, P.H., Hood, L., and van den Engh, G. (1997). Cellcell interaction in prostate gene regulation and cytodifferentiation. Proc Natl Acad Sci U S A 94, 10705-10710.

Liu, X., and Erikson, R.L. (2003). Polo-like kinase (PIk)1 depletion induces apoptosis in cancer cells. Proc Natl Acad Sci U S A 100, 5789-5794.

Liu, X., Zhou, T., Kuriyama, R., and Erikson, R.L. (2004). Molecular interactions of Polo-like-kinase 1 with the mitotic kinesin-like pro- 
tein CHO1/MKLP-1. J Cell Sci 117, 3233-3246.

Liu, X.S., Li, H., Song, B., and Liu, X. (2010a). Polo-like kinase 1 phosphorylation of $\mathrm{G} 2$ and S-phase-expressed 1 protein is essential for $\mathrm{p} 53$ inactivation during $\mathrm{G} 2$ checkpoint recovery. EMBO Rep 11, 626-632.

Liu, X.S., Song, B., Elzey, B.D., Ratliff, T.L., Konieczny, S.F., Cheng, L., Ahmad, N., and Liu, X. (2011). Polo-like kinase 1 facilitates loss of Pten tumor suppressor-induced prostate cancer formation. J Biol Chem 286, 35795-35800.

Liu, X.S., Song, B., and Liu, X. (2010b). The substrates of Plk1, beyond the functions in mitosis. Protein Cell 1, 999-1010.

Llamazares, S., Moreira, A., Tavares, A., Girdham, C., Spruce, B.A., Gonzalez, C., Karess, R.E., Glover, D.M., and Sunkel, C.E. (1991). polo encodes a protein kinase homolog required for mitosis in Drosophila. Genes Dev 5, 2153-2165.

Lu, L.Y., Wood, J.L., Minter-Dykhouse, K., Ye, L., Saunders, T.L., Yu, $X$. , and Chen, J. (2008). Polo-like kinase 1 is essential for early embryonic development and tumor suppression. Mol Cell Biol 28, 6870-6876.

Ma, S., Charron, J., and Erikson, R.L. (2003). Role of Plk2 (Snk) in mouse development and cell proliferation. Mol Cell Biol 23, 6936-6943.

Macmillan, J.C., Hudson, J.W., Bull, S., Dennis, J.W., and Swallow, C.J. (2001). Comparative expression of the mitotic regulators SAK and PLK in colorectal cancer. Ann Surg Oncol 8, 729-740.

Manke, I.A., Lowery, D.M., Nguyen, A., and Yaffe, M.B. (2003). $B R C T$ repeats as phosphopeptide-binding modules involved in protein targeting. Science 302, 636-639.

Martin, B.T., and Strebhardt, K. (2006). Polo-like kinase 1: target and regulator of transcriptional control. Cell Cycle 5, 2881-2885.

Masai, H., Matsumoto, S., You, Z., Yoshizawa-Sugata, N., and Oda, M. (2010). Eukaryotic chromosome DNA replication: where, when, and how? Annu Rev Biochem 79, 89-130.

McNeal, J.E. (1969). Origin and development of carcinoma in the prostate. Cancer 23, 24-34.

McNeal, J.E. (1981). The zonal anatomy of the prostate. Prostate 2, 35-49.

McNeal, J.E. (1988). Normal histology of the prostate. Am J Surg Pathol 12, 619-633.

Moshe, Y., Boulaire, J., Pagano, M., and Hershko, A. (2004). Role of Polo-like kinase in the degradation of early mitotic inhibitor 1 , a regulator of the anaphase promoting complex/cyclosome. Proc Natl Acad Sci U S A 101, 7937-7942.

Mross, K., Frost, A., Steinbild, S., Hedbom, S., Rentschler, J., Kaiser, R., Rouyrre, N., Trommeshauser, D., Hoesl, C.E., and Munzert, G. (2008). Phase I dose escalation and pharmacokinetic study of BI 2536, a novel Polo-like kinase 1 inhibitor, in patients with advanced solid tumors. J Clin Oncol 26, 5511-5517.

Nagle, R.B., Ahmann, F.R., McDaniel, K.M., Paquin, M.L., Clark, V.A., and Celniker, A. (1987). Cytokeratin characterization of human prostatic carcinoma and its derived cell lines. Cancer Res 47, 281-286.

Nakajima, H., Toyoshima-Morimoto, F., Taniguchi, E., and Nishida, E. (2003). Identification of a consensus motif for Plk (Polo-like kinase) phosphorylation reveals Myt1 as a Plk1 substrate. J Biol Chem 278, 25277-25280.

Neef, R., Gruneberg, U., Kopajtich, R., Li, X., Nigg, E.A., Sillje, H., and Barr, F.A. (2007). Choice of Plk1 docking partners during mitosis and cytokinesis is controlled by the activation state of Cdk1. Nat Cell Biol 9, 436-444.

Niiya, F., Tatsumoto, T., Lee, K.S., and Miki, T. (2006). Phosphorylation of the cytokinesis regulator ECT2 at G2/M phase stimulates association of the mitotic kinase Plk1 and accumulation of GTP-bound RhoA. Oncogene 25, 827-837.

Nishimura, Y., and Yonemura, S. (2006). Centralspindlin regulates ECT2 and RhoA accumulation at the equatorial cortex during cytokinesis. J Cell Sci 119, 104-114.

Nishino, M., Kurasawa, Y., Evans, R., Lin, S.-H., Brinkley, B.R., and Yu-Lee, L.Y. (2006). NudC is required for Plk1 targeting to the kinetochore and chromosome congression. Curr Biol 16, 1414-1421.

Olmos, D., Allred, A., Sharma, R., et al. (2009). Phase I first-in-human study of the polo-like kinase-1 selective inhibitor, GSK461364, in patients with advanced solid tumors. J Clin Oncol, 27. [abstract 3536]

Oshimori, N., Ohsugi, M., and Yamamoto, T. (2006). The Plk1 target Kizuna stabilizes mitotic centrosomes to ensure spindle bipolarity. Nat Cell Biol 8, 1095-1101.

Pandha, H.S., Protheroe, A., Wylie, J., et al. (2008). An open label phase II trial of $\mathrm{BI} 2536$, a novel Plk1 inhibitor, in patients with metastatic hormone refractory prostate cancer (HRPC). J Clin Oncol, 26 [abstract 14547]

Park, J.E., Soung, N.K., Johmura, Y., Kang, Y.H., Liao, C., Lee, K.H., Park, C.H., Nicklaus, M.C., and Lee, K.S. (2010). Polo-box domain: a versatile mediator of polo-like kinase function. Cell Mol Life Sci 67, 1957-1970.

Patnaik, A., Forero, L., Goetz, A. et al. (2003). HMN-214, a novel oral antimicrotubular agent and inhibitor of Polo-like- and cyclin-dependent kinases: Clinical, pharmacokinetic (PK) and pharmacodynamic (PD) relationships observed in a phase I trial of a daily $\times 5$ schedule every 28 days. Proc Am Soc Clin Oncol 22, 514.

Pavicic-Kaltenbrunner, V., Mishima, M., and Glotzer, M. (2007). Cooperative assembly of CYK-4/MgcRacGAP and ZEN-4/MKLP1 to form the centralspindlin complex. Mol Biol Cell 18, 4992-5003.

Peehl, D.M. (2005). Primary cell cultures as models of prostate cancer development. Endocr Relat Cancer 12, 19-47.

Petronczki, M., Lénárt, P., and Peters, J.M. (2008). Polo on the Rise-from Mitotic Entry to Cytokinesis with Plk1. Dev Cell 14, 646-659.

Qi, W., Tang, Z., and Yu, H. (2006). Phosphorylation- and polo-boxdependent binding of Plk1 to Bub1 is required for the kinetochore localization of Plk1. Mol Biol Cell 17, 3705-3716.

Reagan-Shaw, S., and Ahmad, N. (2005a). Polo-like kinase (Plk) 1 as a target for prostate cancer management. IUBMB Life 57 , $677-682$.

Reagan-Shaw, S., and Ahmad, N. (2005b). Silencing of polo-like kinase (Plk) 1 via siRNA causes induction of apoptosis and impairment of mitosis machinery in human prostate cancer cells: implications for the treatment of prostate cancer. The FASEB J 19, 611-613.

Reid, A.H.M., Attard, G., Ambroisine, L., Fisher, G., Kovacs, G., Brewer, D., Clark, J., Flohr, P., Edwards, S., Berney, D.M., et al., and the Transatlantic Prostate Group. (2010). Molecular charac- 
terisation of ERG, ETV1 and PTEN gene loci identifies patients at low and high risk of death from prostate cancer. $\mathrm{Br} \mathrm{J}$ Cancer 102, 678-684.

Reindl, W., Strebhardt, K., and Berg, T. (2008b). A high-throughput assay based on fluorescence polarization for inhibitors of the polo-box domain of polo-like kinase 1. Anal Biochem 383, 205-209.

Reindl, W., Yuan, J., Krämer, A., Strebhardt, K., and Berg, T. (2008a). Inhibition of polo-like kinase 1 by blocking polo-box domain-dependent protein-protein interactions. Chem Biol 15, 459-466.

Reindl, W., Yuan, J., Krämer, A., Strebhardt, K., and Berg, T. (2009). A pan-specific inhibitor of the polo-box domains of polo-like kinases arrests cancer cells in mitosis. Chembiochem 10, 1145-1148.

Rosasco-Nitcher, S.E., Lan, W., Khorasanizadeh, S., and Stukenberg, P.T. (2008). Centromeric Aurora-B activation requires TD-60, microtubules, and substrate priming phosphorylation. Science 319 , 469-472.

Santamaria, A., Neef, R., Eberspächer, U., Eis, K., Husemann, M., Mumberg, D., Prechtl, S., Schulze, V., Siemeister, G., Wortmann, L., et al. (2007). Use of the novel Plk1 inhibitor ZK-thiazolidinone to elucidate functions of Plk1 in early and late stages of mitosis. Mol Biol Cell 18, 4024-4036.

Sebastian, M., Reck, M., Digel, W., et al. (2009). Impact of BI2536, a novel Plk1 inhibitor, on disease progression and quality of life parameters in patients with non-small cell lung cancer: results of a randomized phase II trial. Ann Oncol, 19. [abstract 295]

Sehnoy, A., Pfannes, L., Wilhelm, F., et al. (2008). Suppression of cyclin D 1(CD1) by ON 01910.Na is associated with decreased survival or trisomy 8 myelodysplastic bone marrow: a potential targeted therapy for trisomy 8 MDS. Blood, 112. [abstract 1651]

Shappell, S.B., Thomas, G.V., Roberts, R.L., Herbert, R., Ittmann, M.M., Rubin, M.A., Humphrey, P.A., Sundberg, J.P., Rozengurt, N., Barrios, R., et al., and the The Consensus Report from the Bar Harbor Meeting of the Mouse Models of Human Cancer Consortium Prostate Pathology Committee. (2004). Prostate pathology of genetically engineered mice: definitions and classification. The consensus report from the Bar Harbor meeting of the Mouse Models of Human Cancer Consortium Prostate Pathology Committee. Cancer Res 64, 2270-2305.

Shen, M.M., and Abate-Shen, C. (2010). Molecular genetics of prostate cancer: new prospects for old challenges. Genes Dev 24, 1967-2000.

Shirayama, M., Zachariae, W., Ciosk, R., and Nasmyth, K. (1998). The Polo-like kinase Cdc5p and the WD-repeat protein Cdc20p/fizzy are regulators and substrates of the anaphase promoting complex in Saccharomyces cerevisiae. EMBO J 17, 1336-1349.

Smith, M.R., Wilson, M.L., Hamanaka, R., Chase, D., Kung, H., Longo, D.L., and Ferris, D.K. (1997). Malignant transformation of mammalian cells initiated by constitutive expression of the polo-like kinase. Biochem Biophys Res Commun 234, 397-405.

Somers, W.G., and Saint, R. (2003). A RhoGEF and Rho family GTPase-activating protein complex links the contractile ring to cortical microtubules at the onset of cytokinesis. Dev Cell 4, 29-39.

Song, B., Liu, X.S., Davis, K., and Liu, X. (2011). Plk1 phosphoryla- tion of Orc2 promotes DNA replication under conditions of stress. Mol Cell Biol 31, 4844-4856.

Spänkuch, B., Matthess, Y., Knecht, R., Zimmer, B., Kaufmann, M., and Strebhardt, K. (2004). Cancer inhibition in nude mice after systemic application of U6 promoter-driven short hairpin RNAs against PLK1. J Natl Cancer Inst 96, 862-872.

Steegmaier, M., Hoffmann, M., Baum, A., Lénárt, P., Petronczki, M., Krssák, M., Gürtler, U., Garin-Chesa, P., Lieb, S., Quant, J., et al. (2007). BI 2536, a potent and selective inhibitor of polo-like kinase 1 , inhibits tumor growth in vivo. Curr Biol 17, 316-322.

Strebhardt, K. (2010). Multifaceted polo-like kinases: drug targets and antitargets for cancer therapy. Nat Rev Drug Discov 9, 643-660.

Strebhardt, K., Kneisel, L., Linhart, C., Bernd, A., and Kaufmann, R. (2000). Prognostic value of pololike kinase expression in melanomas. JAMA 283, 479-480.

Strebhardt, K., and Ullrich, A. (2006). Targeting polo-like kinase 1 for cancer therapy. Nat Rev Cancer 6, 321-330.

Stuermer, A., Hoehn, K., Faul, T., Auth, T., Brand, N., Kneissl, M., Pütter, V., and Grummt, F. (2007). Mouse pre-replicative complex proteins colocalise and interact with the centrosome. Eur $\mathrm{J}$ Cell Biol 86, 37-50.

Syljuåsen, R.G., Jensen, S., Bartek, J., and Lukas, J. (2006). Adaptation to the ionizing radiation-induced $\mathrm{G} 2$ checkpoint occurs in human cells and depends on checkpoint kinase 1 and Polo-like kinase 1 kinases. Cancer Res 66, 10253-10257.

Takahashi, T., Sano, B., Nagata, T., Kato, H., Sugiyama, Y., Kunieda, K., Kimura, M., Okano, Y., and Saji, S. (2003). Polo-like kinase 1 (PLK1) is overexpressed in primary colorectal cancers. Cancer Sci 94, 148-152.

Takai, N., Hamanaka, R., Yoshimatsu, J., and Miyakawa, I. (2005). Polo-like kinases (Plks) and cancer. Oncogene 24, 287-291.

Takai, N., Miyazaki, T., Fujisawa, K., Nasu, K., Hamanaka, R., and Miyakawa, I. (2001a). Expression of polo-like kinase in ovarian cancer is associated with histological grade and clinical stage. Cancer Lett 164, 41-49.

Takai, N., Miyazaki, T., Fujisawa, K., Nasu, K., Hamanaka, R., and Miyakawa, I. (2001b). Polo-like kinase (PLK) expression in endometrial carcinoma. Cancer Lett 169, 41-49.

Takaki, T., Trenz, K., Costanzo, V., and Petronczki, M. (2008). Polo-like kinase 1 reaches beyond mitosis-cytokinesis, DNA damage response, and development. Curr Opin Cell Biol 20, 650-660.

Taylor, B.S., Schultz, N., Hieronymus, H., Gopalan, A., Xiao, Y., Carver, B.S., Arora, V.K., Kaushik, P., Cerami, E., Reva, B., et al. (2010). Integrative genomic profiling of human prostate cancer. Cancer Cell 18, 11-22.

Timms, B.G. (2008). Prostate development: a historical perspective. Differentiation 76, 565-577.

Toczyski, D.P., Galgoczy, D.J., and Hartwell, L.H. (1997). CDC5 and CKII control adaptation to the yeast DNA damage checkpoint. Cell 90, 1097-1106.

Tokumitsu, Y., Mori, M., Tanaka, S., Akazawa, K., Nakano, S., and Niho, Y. (1999). Prognostic significance of polo-like kinase expression in esophageal carcinoma. Int J Oncol 15, 687-692.

Toyoshima-Morimoto, F., Taniguchi, E., and Nishida, E. (2002). Plk1 promotes nuclear translocation of human $\mathrm{Cdc} 25 \mathrm{C}$ during prophase. EMBO Rep 3, 341-348. 
Toyoshima-Morimoto, F., Taniguchi, E., Shinya, N., Iwamatsu, A., and Nishida, E. (2001). Polo-like kinase 1 phosphorylates cyclin B1 and targets it to the nucleus during prophase. Nature 410, 215-220.

Tsvetkov, L., and Stern, D.F. (2005). Interaction of chromatin-associated Plk1 and Mcm7. J Biol Chem 280, 11943-11947.

van de Weerdt, B.C., and Medema, R.H. (2006). Polo-like kinases: a team in control of the division. Cell Cycle 5, 853-864.

van Leenders, G.J.L.H., and Schalken, J.A. (2003). Epithelial cell differentiation in the human prostate epithelium: implications for the pathogenesis and therapy of prostate cancer. Crit Rev Oncol Hematol 46, S3-S10.

van Vugt, M.A.T.M., Gardino, A.K., Linding, R., Ostheimer, G.J., Reinhardt, H.C., Ong, S.-E., Tan, C.S., Miao, H., Keezer, S.M., Li, J., et al. (2010). A mitotic phosphorylation feedback network connects Cdk1, Plk1, 53BP1, and Chk2 to inactivate the $\mathrm{G}(2) / \mathrm{M}$ DNA damage checkpoint. PLoS Biol 8, e1000287.

von Hoff, D.D., Taylor, C., Rubin, S., et al. (2004). A phase I and pharmacokinetic study of $\mathrm{HMN}-214$, a novel oral Polo-like kinase inhibitor, in patients with advanced solid tumors. [abstract] J Clin Oncol 22, 3034.

Vose, J., Young, A., Friedberg, J.W., et al. (2008). Phase I dose-escalation trial of $\mathrm{BI} 2536$, a polo-like kinase 1 inhibitor, in relapsed and refractory Non-Hodgkin's lymphoma. Blood 112. [abstract 233]

Wäsch, R., and Engelbert, D. (2005). Anaphase-promoting complex-dependent proteolysis of cell cycle regulators and genomic instability of cancer cells. Oncogene 24, 1-10.

Watanabe, N., Arai, H., Nishihara, Y., Taniguchi, M., Watanabe, N., Hunter, T., and Osada, H. (2004). M-phase kinases induce phospho-dependent ubiquitination of somatic Wee1 by SCFbeta-TrCP. Proc Natl Acad Sci U S A 101, 4419-4424.

Watanabe, N., Sekine, T., Takagi, M., Iwasaki, J., Imamoto, N., Kawasaki, H., and Osada, H. (2009). Deficiency in chromosome congression by the inhibition of Plk1 polo box domain-dependent recognition. J Biol Chem 284, 2344-2353.

Weichert, W., Denkert, C., Schmidt, M., Gekeler, V., Wolf, G., Köbel, M., Dietel, M., and Hauptmann, S. (2004a). Polo-like kinase isoform expression is a prognostic factor in ovarian carcinoma. $\mathrm{Br} \mathrm{J}$ Cancer 90, 815-821.

Weichert, W., Schmidt, M., Gekeler, V., Denkert, C., Stephan, C., Jung, K., Loening, S., Dietel, M., and Kristiansen, G. (2004b). Polo-like kinase 1 is overexpressed in prostate cancer and linked to higher tumor grades. Prostate 60, 240-245.

Wolf, G., Elez, R., Doermer, A., Holtrich, U., Ackermann, H., Stutte, H.J., Altmannsberger, H.M., Rübsamen-Waigmann, H., and Strebhardt, K. (1997). Prognostic significance of polo-like kinase
(PLK) expression in non-small cell lung cancer. Oncogene 14, 543-549.

Wolf, G., Hildenbrand, R., Schwar, C., Grobholz, R., Kaufmann, M., Stutte, H.J., Strebhardt, K., and Bleyl, U. (2000). Polo-like kinase: a novel marker of proliferation: correlation with estrogen-receptor expression in human breast cancer. Pathol Res Pract 196, 753-759.

Wolfe, B.A., Takaki, T., Petronczki, M., and Glotzer, M. (2009). Polo-like kinase 1 directs assembly of the HsCyk-4 RhoGAP/Ect2 RhoGEF complex to initiate cleavage furrow formation. PLoS Biol 7, e1000110.

Wong, O.K., and Fang, G. (2005). Plx1 is the 3F3/2 kinase responsible for targeting spindle checkpoint proteins to kinetochores. J Cell Biol 170, 709-719.

Wu, Z.Q., and Liu, X. (2008). Role for Plk1 phosphorylation of Hbo1 in regulation of replication licensing. Proc Natl Acad Sci U S A 105, 1919-1924.

Wu, Z.Q., Yang, X., Weber, G., and Liu, X. (2008). Plk1 phosphorylation of TRF1 is essential for its binding to telomeres. J Biol Chem 283, 25503-25513.

Yang, X., Li, H., Liu, X.S., Deng, A., and Liu, X. (2009a). Cdc2-mediated phosphorylation of CLIP-170 is essential for its inhibition of centrosome reduplication. J Biol Chem 284, 28775-28782.

Yang, X., Li, H., Zhou, Z., Wang, W.H., Deng, A., Andrisani, O., and Liu, X. (2009b). Plk1-mediated phosphorylation of Topors regulates p53 stability. J Biol Chem 284, 18588-18592.

Yim, H., and Erikson, R.L. (2009). Polo-like kinase 1 depletion induces DNA damage in early $S$ prior to caspase activation. Mol Cell Biol 29, 2609-2621.

Yoo, H.Y., Kumagai, A., Shevchenko, A., Shevchenko, A., and Dunphy, W.G. (2004). Adaptation of a DNA replication checkpoint response depends upon inactivation of Claspin by the Polo-like kinase. Cell 117, 575-588.

Yuan, J., Eckerdt, F., Bereiter-Hahn, J., Kurunci-Csacsko, E., Kaufmann, M., and Strebhardt, K. (2002). Cooperative phosphorylation including the activity of polo-like kinase 1 regulates the subcellular localization of cyclin B1. Oncogene 21, 8282-8292.

Yüce, O., Piekny, A., and Glotzer, M. (2005). An ECT2-centralspindlin complex regulates the localization and function of RhoA. J Cell Biol 170, 571-582.

Zhao, W.M., and Fang, G. (2005). MgcRacGAP controls the assembly of the contractile ring and the initiation of cytokinesis. Proc Natl Acad Sci U S A 102, 13158-13163.

Zhou, T., Aumais, J.P., Liu, X., Yu-Lee, L.-Y., and Erikson, R.L. (2003). A role for Plk1 phosphorylation of NudC in cytokinesis. Dev Cell 5, 127-138. 